\title{
From Merck's CCK- Antagonists Via 4-Amino-2(5H)- Furanones towards 5-Hydroxy-Pyrrol-2-Ones: Design, Synthesis and Evaluation of PNB-001 \& PNB-081 as Experimental Therapeutic Agents in Pain Management
}

\author{
Eric Lattmann ${ }^{1 *}$, JintanaSattayasai ${ }^{2}$, Ramesh Narayanan ${ }^{3}$, Julian Benyamen ${ }^{1}$, PN Balaram ${ }^{4}$ and Pornthip \\ Lattmann $^{4}$ \\ ${ }^{1}$ School of Life and Health Sciences, Aston University, England \\ ${ }^{2}$ Department of Pharmacology, KhonKaen University, Thailand
}

${ }^{3}$ Department of Medicine, University of Tennessee Health Science Center, USA

${ }^{4}$ PNB Vesper Life Science PVT, India

Received: 制 March 20, 2018; Published: 眥 March 27, 2018

*Corresponding author: Eric Lattmann, School of Life and Health Sciences, Aston University, England

\begin{abstract}
Arylated 5-hydroxy-pyrrol-2-ones were prepared in 2 synthetic steps from muco-chloric acid and were optimised as $\mathrm{CCK}_{1} /$ $\mathrm{CCK}_{2}$ selective ligands using radio labelled binding assays. A potent $\mathrm{CCK}_{1}$ selective ligand was identified (PNB-081: CCK1=20nM) as well as a potent $\mathrm{CCK}_{2}$ ligand (PNB-001, IC50 $=22 \mathrm{nM}$ ) during a systematic SAR optimisation. The antagonism was confirmed for both ligands by using isolated tissue preparations with $\mathrm{CCK}_{5}$ and CCK8S. Subsequent in vivo evaluation revealed analgesic activity for the gastrin $\mathrm{CCK}_{2}$ antagonist PNB-001, in the hotplate and tail immersion test at $0.5 \mathrm{mg} / \mathrm{kg}$ by IP administration in mice. The cholecystokinin antagonist PNB-081 potentiated the analgesic effect of morphine and reversed opiate tolerance in mice from doses $>1 \mathrm{mg} / \mathrm{kg}$ by oral administration.
\end{abstract}

Keywords: Phenyl-Pyrolone; CCK Antagonist; Cholecystokinin; Analgesic; Opiate Adjunct

Abbreviations: GIT: Gastrointestinal Tract; TT: Test Thresholds; BT: Base Line Withdrawal Thresholds; ANOVA: Analysis Of Variance

\section{Introduction}

In terms of cholecystokinin-physiology [1], CCK8is the most common peptide hormone, which is extensively found throughout the gastrointestinal tract (GIT) and is also widely distributed through the nervous system [2]. Originally, cholecystokinin was discovered to cause contractions of the gallbladder [3]. It was then rediscovered as pancreozymin, triggering the release of pancreatic enzymes. Finally, it was confirmed that both peptides are identical [4]. Cholecystokinin acts as a neuro modulator as well as gut hormone. CCK-ligands, agonists and antagonists have been extensively investigated as potential drug molecules [5]. Cholecystokinin antagonists have been extensively investigated as potential drug targets [6]. They were studied as growth inhibitors in certain forms of cancer [7], as anxiolytics [8], in the treatment of schizophrenia [9] and satiety [10]. An agonist, the shortened $\mathrm{CCK}_{4}$ was found to induce panic in patients [11] and the $\mathrm{CCK}_{2}$ receptor is known to mediate anxiety [12] and panic attacks [13]. Cholecystokinin does cause proliferation in colon- and pancreatic cancer cell lines and therefore, CCK-antagonists were studied as growth factor inhibitors in certain forms of cancer. Asperlicin was the first non-peptidal lead structure from nature [14] and analogues thereof were studied as CCK ligands [15]. Simplification of this lead structure by Merck led to Devazepide [16], a potent $\mathrm{CCK}_{1}$ selective cholecystokinin antagonist (Figure 1a), containing a 1,4-benzodiazepine template and an indole moiety. 


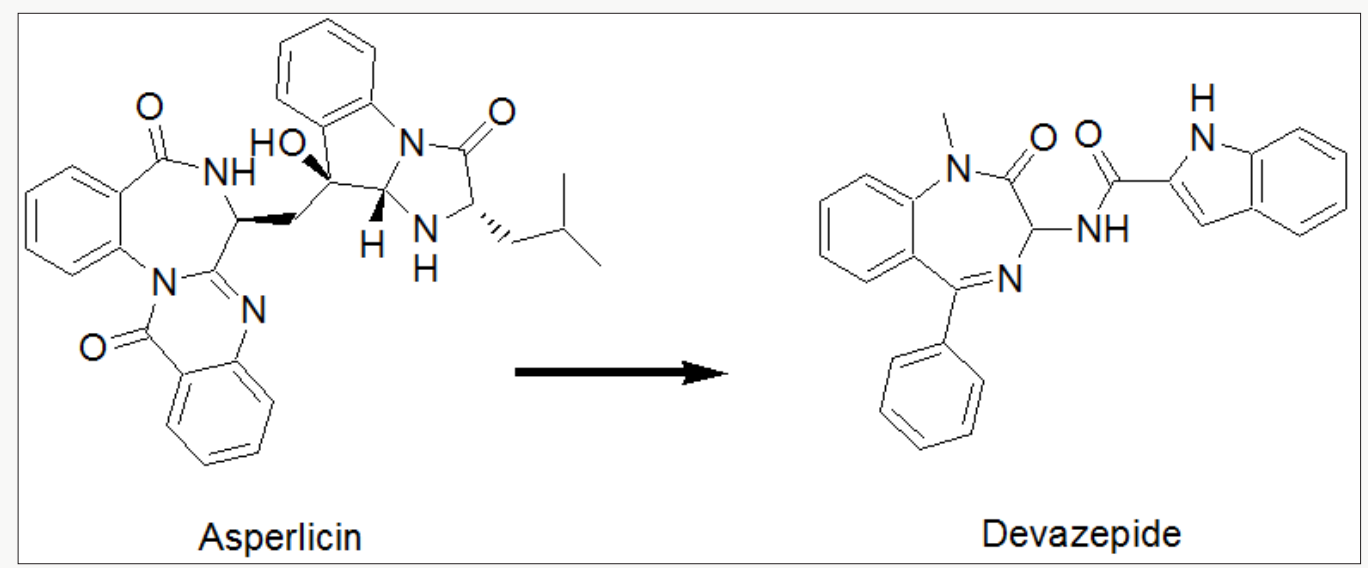

Figure 1a: Discovery; Merck's CCK patents. From the natural product asperlicin to a fully synthetic 1,4-benzodiazepine lead structure.

Proglumide [17] was the first glutamic acid based agent, marketed as Milid for the treatment of ulcer. Lorglumide, a derivative of proglumide [18], (Figure 1b) is one of several CCK receptor antagonists [19] and served as experimental standard. The indolyl amide of devazepide was replaced by a urea linkage and Merck's L-365,260 resulted in a $\mathrm{CCK}_{2}$ selective antagonist [20]. Further subsequent SAR optimization led to Zeria's improved Z-360
[21], in which the $\mathrm{N}$-alkyl side chain, the 5- position (cyclohexyl) was optimized for potency and a meta-carboxylic acid on the aryl urea linkage was introduced to enhance water solubility (Figure 1c). Z-360 is a $\mathrm{CCK}_{2}$-gastrin receptor antagonist and progressed into phase 2 trial with pancreatic cancer [22]. Z-360 is the most recent derivative derived from this original lead structure, with improved selectivity and bioavailability.

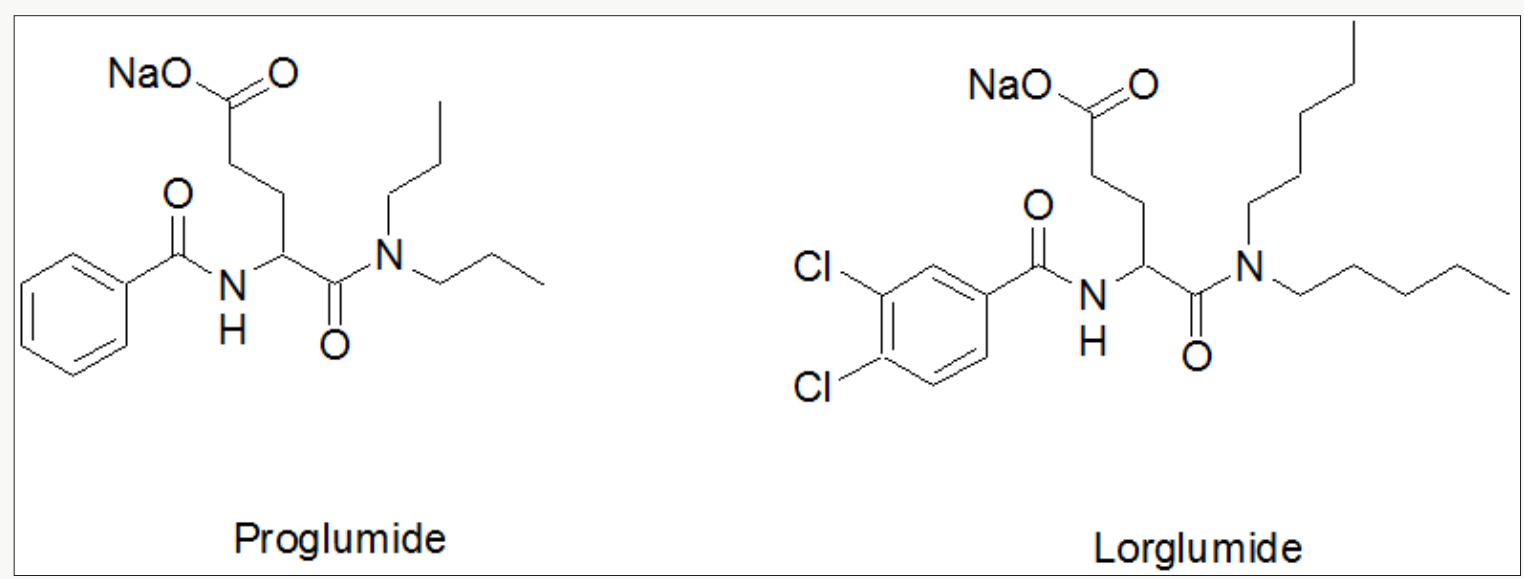

Figure 1b: Cholecystokinin standard-Lorglumide. Rotta Research Labs. Patents based on glutamic acid, agents with little membrane penetration.
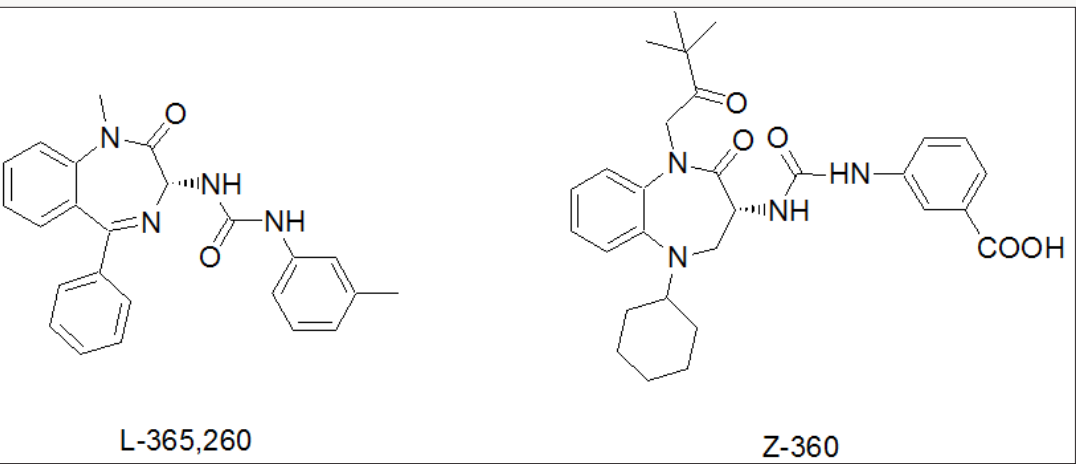

Figure 1c: Merck's SAR optimisation from Devazepide towards a gastrin antagonist L-365,260 with final optimisation by Zeria Ltd and selection patent on Z-360. 
All structural optimisations did only partly address the main underlying problem with respect to poor pharmacokinetic properties, such as a low water solubility and very low membrane penetration, as a result of a large polar surface area of the molecules and a relatively high molecular weight. In our early search for new CCK ligands, in which the 1, 4-benzodiazepine structure [23] was replaced by an achiral diphenyl pyrazolone template, novel CCK antagonists with an indole carboxylic acid [24] and a phenyl urea moiety [25] were found and optimized with excellent animal data on anxiety and depression [26]. The patent was discontinued as structure was part of a Chinese molecular modelling patent application (Figure 1d). The 1,4-benzodiazepine template was varied by a combinatorial solid phase synthesis [27] and it was SAR optimised in terms of CCK binding affinity to a benzodiazepine with a simple propyl group [28]. Again, having realized the poor pharmacokinetic properties these agents, a search for a completely novel, smaller template with a molecular weight $<350$, a log $p$ about 3 and a polar surface area for membrane penetration of less that $100 \mathrm{~A}$, with no urea linkage was initiated. Aim of the drug discovery programme, initiated by PNB Vesper Life Sciences, was to systematically investigate and design the $2(5 \mathrm{H})$-furanone scaffold [29] in to a hydroxy-pyrolone scaffold with ligands for both CCK pathways (Figure 1e). Molecular pain targets have been reviewed recently [30] and the results are quite disappointing in terms of efficacy and FDA approval rate. Even, this review missed out on CCK antagonists [31] and most importantly on a very positive report, publicised only in form of an abstract [32]. In summary in this study, devazepide at $5 \mathrm{mg}$ was found very efficient in pain management as adjunct to strong opiates in a phase 2 trial carried out at leading UK pain research centres. Initial results for CCK antagonists of the pyrolone scaffold were communicated in the area of cancer therapeutics [33] and GI inflammation [34]. Here, a full biological evaluation of PNB Vesper Life Science's pain moleculesPNB-001\& PNB-081, which are covered by an original patent, are reported in detail here with respect to pain management [35].<smiles>COc1cccc(NC(=O)Nc2c(C)n(-c3ccccc3)n(-c3ccccc3)c2=O)c1</smiles><smiles>Cc1c(NC(=O)CCc2c[nH]c3ccccc23)c(=O)n(-c2ccccc2)n1-c1ccccc1</smiles>

\section{Urea}

Amide

Figure 1d: Urea / Amide based CCK antagonists covered by Aston University patent replacing the 1,4-benzodiazepine scaffold with a pyrazole.

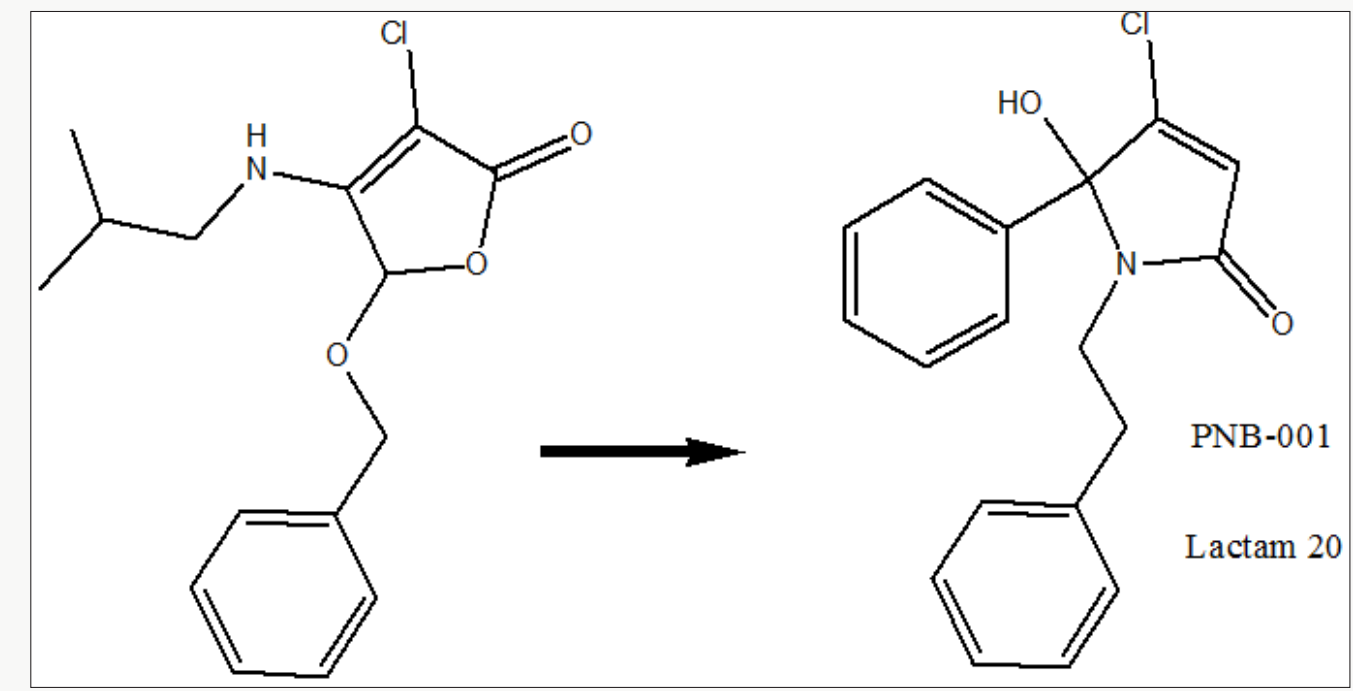

Figure 1e: From lactones to lactams. Discovery of pyrolones as a novel CCK-template. From an Aston University user patent on 4-amino-2(5H)-furanonesto a novel original template. 


\section{Results and Discussions}

\section{Chemistry}

5-arylated dichloro-2(5H)-furanones A and B were synthesised from muco-chloric acid (Scheme 1), which is commercially available from furfural under oxidising conditions with hydrochloric acid. Theses intermediates were evaluated previously as anticancer agents [36]. Muco-chloric acid was reacted with benzene as reagent and solvent at RT under the development of hydrogen chloride gas. Depending on the scale of the reaction cooling with ice was required. For chloro benzene / benzene the powdered or most preferred granulated aluminium chloride served as the best catalyst and during work up with hydrochloric acid on ice the inorganic salts were easily removed from the organic phase. In terms of scope of the reaction arylated $2(5 \mathrm{H})$-furanones, containing nitro- groups or trifluoro-methyl groups could not be prepared. For the small scale synthesis aluminium chloride worked well as Lewis acid. However, during scale up aluminium chloride was replaced by trifluoroborane in THF as the exothermic reaction become problematic on a kg scale.

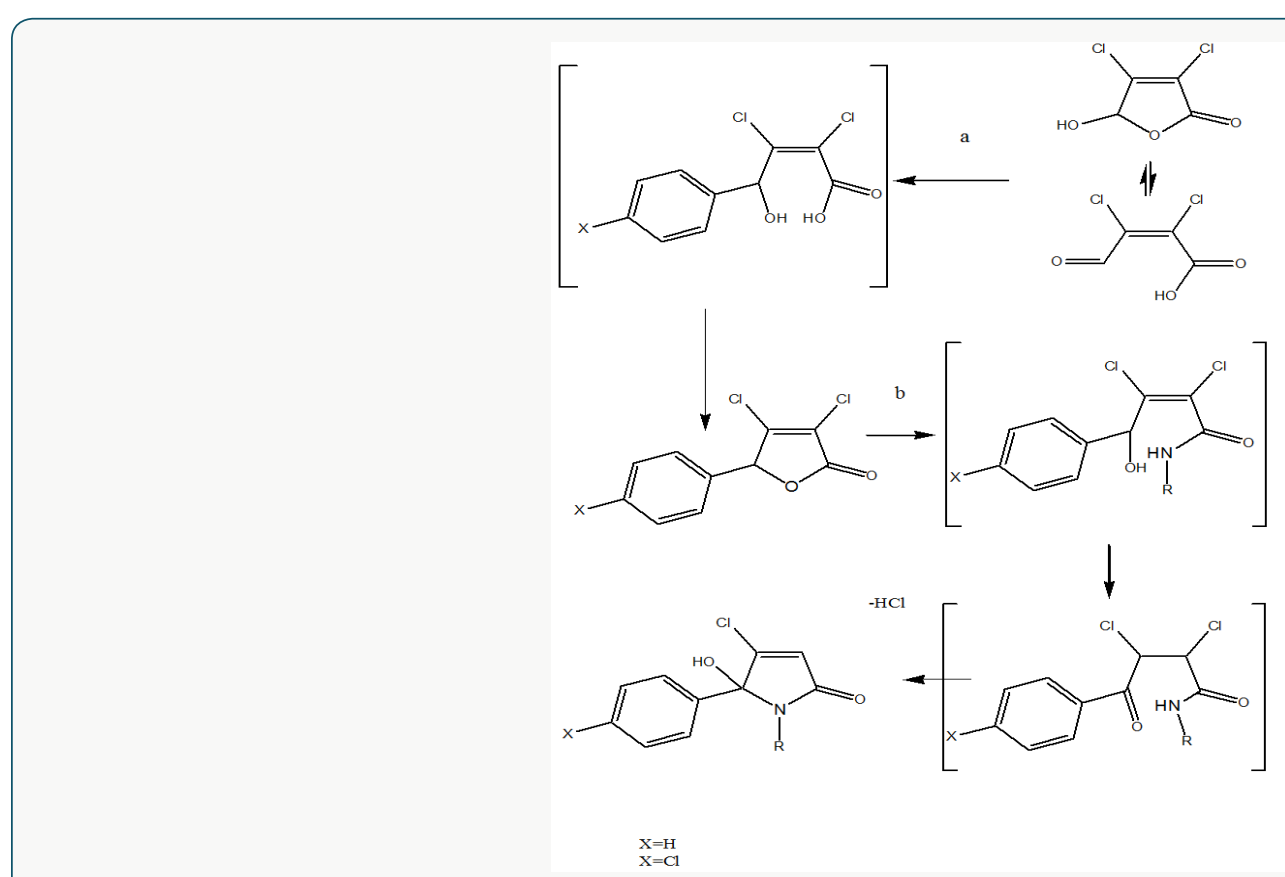

Scheme 1: Synthesis and chemical mechanism for the preparation of lactams1-21 from muco-chloric acid.

a) Arene, RT, 10 h, workup: hydrochloric acid; b) amine , excess, ether, RT, 30 min

Subsequent reaction of the 5-arylated 3,4-dichloro-2(5H)furanones A and B (Stage 1 intermediate) in diethyl ether with alkyland aryl alkyl amines furnished N-alkylated hydroxyl-pyrrolones121(Stage 2 products) in high yields under mild conditions. The general synthetic sequence is outlined in Scheme 1.

Overall, the desired $\mathrm{N}$-alkylated unsubstituted 5-phenyl pyrrolones1-21 was obtained in only a 2 stage process as white crystalline material. The molecule is not present in the ring opened keto form and fully occurred in the 5-membered ring form, as a hydroxy-pyrolone. The 5-arylated $2(5 \mathrm{H})$-furanones reacted selectively in the ester position and no reaction in the 4-position was observed here. Previously the IPSO substitution (4-position) was described for pseudo- esters [37], and here in Scheme 1, a ringopening ring-closure mechanism is proposed for the formation of hydroxy-pyrolone. Thus, the first step in the reaction sequence of the dichlorinated $2(5 \mathrm{H})$-furanone is the ring opening and amide formation from the corresponding lactone. Subsequently, the keto form of the acyclic amide was in situ converted into a lactam under the elimination of hydrogen chloride (middle, scheme 1). The analysis of lactam 7 and 20by chiral HPLC showed a 50:50 racemic mixture of both enantiomers in solution in methanol.

\section{SAR Optimisation}

The first step was to screen for potent binding affinity and to identify a $\mathrm{CCK}_{1}$ or $\mathrm{CCK}_{2}$-selective ligand for subsequent in vitro and in vivo evaluation. Using radio labelled iodinated cholecystokinin, inhibition of binding was determined for all test molecules and the $\mathrm{IC}_{50}$ are outlined in (Table 1). Lorglumide served as $\mathrm{CCK}_{1}$ standard and L-365,260 was used as $\mathrm{CCK}_{2}$ standard. Hydroxy-pyrolones containing an N-methyl group, present in lactam1-2, showed no binding affinity and an increase in the length of the $\mathrm{N}$ - side chain resulted in micro molar binding affinity for the isopropyl group, as seen in lactam3 and 4. Ring closure on the N-substituent, from isopropyl to cyclo-propyl resulted in a loss of activity (lactam5, 6) and the ring enlargement from a 3-membered to a 5- membered ring system (entry 10-11) resulted in no significant increase of binding affinity. The change from N-Propyl into the N-butyl group resulted in a manifold increase of activity and the best 
substituent on the central nitrogen atom was found iso-butyl, as seen for derivative 7. The introduction of a halogen atom into the Para-position of the phenyl group resulted in an increase of binding affinity, possibly due to enhanced lipophilicity. The isobutyl group on the $\mathrm{N}$-atom produced the best overall ligand, with $\mathrm{CCK}_{1}$ selectivity and the $\mathrm{IC}_{50}$ was reduced significantly for t-butyl derivative 9. The n-pentylanalogue was formed in very low yields and the n-hexyl lactam 12, 13 clearly lost binding affinity and the same was observed for the cyclohexyl-derivative 14. Lactam, such as pyrrolone15, containing an aromatic ring, directly connected Table 1: CCK binding affinity expressed in IC50 in micro molar using iodinated hot CCK8 as radio ligands with cortex and pancreatic membranes; $\mathrm{N}=3$. to the N-position, showed a micro molar activity $>10 \mu \mathrm{M}$. Most interestingly, the introduction of an N-benzyl substituent to the pyrolone template, instead of an alkyl group, resulted in nonselective CCK-ligand, pyrrolone16. Again, halogen atoms, such as chlorine, only marginally changed the binding affinity for the chlorinated N-benzyl lactam17.The introduction of a chiral amine, such as methyl benzyl amine provided diastereoisomers (Entry 18, 19), which were separated by column chromatography, and both stereoisomers occurred a lower affinity than the parent benzyl derivative 16 .

\begin{tabular}{|c|c|c|c|c|}
\hline Lactam & $\mathrm{X}=$ & $\mathrm{R}=$ & CCK1 $[\mu \mathrm{M}]$ & $\mathrm{CCK} 2[\mu \mathrm{M}]$ \\
\hline 1 & $\mathrm{H}$ & Methyl- & $2.5 \pm 0.2$ & $>10$ \\
\hline 2 & $\mathrm{Cl}$ & Methyl- & $2.0 \pm 0.2$ & $>10$ \\
\hline 3 & $\mathrm{H}$ & I-Propyl- & $0.2 \pm 0.02$ & $0.9 \pm 0.03$ \\
\hline 4 & $\mathrm{Cl}$ & I-Propyl- & $0.3 \pm 0.04$ & $3.7 \pm 0.4$ \\
\hline 5 & $\mathrm{H}$ & Cyclopropyl- & $7.5 \pm 0.4$ & $>10$ \\
\hline 6 & $\mathrm{Cl}$ & Cyclopropyl- & $4.0 \pm 0.2$ & $>10$ \\
\hline 7 & $\mathrm{H}$ & Isobutyl- & $0.020 \pm 0.01$ & $1.2 \pm 0.3$ \\
\hline 8 & $\mathrm{Cl}$ & Isobutyl- & $0.008 \pm 0.01$ & $0.4 \pm 0.2$ \\
\hline 9 & $\mathrm{H}$ & t-butyl- & $0.12 \pm 0.22$ & $0.9 \pm 0.03$ \\
\hline 10 & $\mathrm{H}$ & Cyclopentyl- & $0.36 \pm 0.03$ & $0.84 \pm 0.2$ \\
\hline 11 & $\mathrm{Cl}$ & Cyclopentyl- & $2.5 \pm 0.03$ & $>10$ \\
\hline 12 & $\mathrm{H}$ & Hexyl- & $4.5 \pm 0.3$ & $>10$ \\
\hline 13 & $\mathrm{Cl}$ & Hexyl- & $3.6 \pm 0.3$ & $>10$ \\
\hline 14 & $\mathrm{H}$ & Cyclohexyl- & $2.5 \pm 0.3$ & $>10$ \\
\hline 15 & $\mathrm{H}$ & Phenyl- & $>10$ & $>10$ \\
\hline 16 & $\mathrm{H}$ & Benzyl- & $0.85 \pm 0.03$ & $0.020 \pm 0.005$ \\
\hline 17 & $\mathrm{Cl}$ & Benzyl- & $0.51 \pm 0.004$ & $0.022 \pm 0.004$ \\
\hline 18 & $\mathrm{H}$ & Methylbenzyl- & $0.6 \pm 0.04$ & $0.21 \pm 0.01$ \\
\hline 19 & $\mathrm{H}$ & Methylbenzyl- & $0.42 \pm 0.03$ & $0.21 \pm 0.15$ \\
\hline 20 & $\mathrm{H}$ & Phenylethyl- & $>10$ & $0.022 \pm 0.002$ \\
\hline 21 & $\mathrm{Cl}$ & Phenylethyl & $>10$ & $0.030 \pm 0.001$ \\
\hline Lorglumide & - & - & $0.17 \pm 0.01$ & $>10$ \\
\hline L-356,260 & - & - & $0.25 \pm 0.01$ & $0.003 \pm 0.001$ \\
\hline
\end{tabular}

The introduction of a spacer, a single $\mathrm{CH}_{2}$ group, resulted in a phenyl-ethyl derivative 20, which represented a highly $\mathrm{CCK}_{2}$ selective ligand. Lactam 20 is 450 times selective for the $\mathrm{CCK}_{2}$ / gastrin receptor. Halogenation, the introduction of a para-chlorine atom on the phenyl-position, lactam 21, did not enhance binding affinity any further; possibly due to drug receptor interaction of the phenyl group with a lipophilic cavity within the CCK receptor. Overall, the introduction of alkyl groups, most preferred an isobutylgroup, provided a $\mathrm{CCK}_{1}$ selective antagonist PNB-081, which was the selected development candidate. A fluorinated analogue had potent anticancer properties via the CCKC receptor [38]. The phenyl-ethyl hydroxyl-pyrolone, lactam20=PNB-001 is $\mathrm{CCK}_{2} /$ gastrin selective antagonist, outlined in (Figure 2). The phenyl ethyl derivative PNB-001 completed preclinical development as anti-inflammatory analgesic and progressed into Phase 1 clinical trials for the treatment of arthritic pain. Lactam8 (pA2 = 8.1) has a nominally higher binding affinity compared with lactam7 (Lactam7=PNB-081, pA2=7.7) but they were found identical in vivo. In addition PNB-081 has a higher melting point (higher chemical stability) and better physical properties (crystal properties). It can be produced during scale up with an increasing chemical yield and excellent (>99.7 \%) purity, required by cGMP synthesis. Therefore, PNB-081 chosen for preclinical development. Most importantly, in vivo it may be metabolized into its para hydroxy-analogue, in line with its pharmacological profile. 


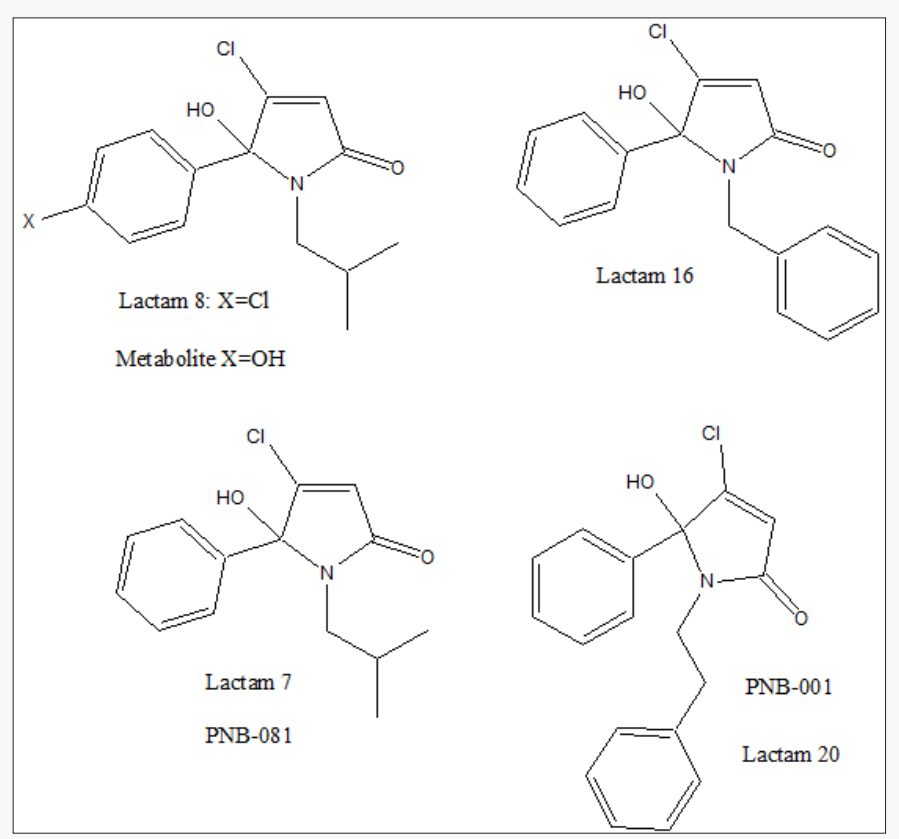

Figure 2: Overview of selective $\mathrm{CCK}_{1}$, mixed and $\mathrm{CCK}_{2}$ antagonists.

\section{Molecular Modelling}

The docking of PNB-001 into the $\mathrm{CCK}_{2}$ receptor is outlined in (Figure 3a) and some key interactions are highlighted for one final pose of minimal energy. The 5-hydroxy group of the central pyrolone template interacted via hydrogen binding with the $\mathrm{N}$ group of Trp114. The phenyl group of the N-phenyl ethyl- side chain bound to the aromatic indole system of Trp114 and electron withdrawing groups may enhance these aromatic interactions. The lipophilic pocket allowed principally a wide range of substituents, but only phenyl and not cyclo-hexyl could be realised synthetically. The 5- phenyl group of the pyrolone template bound via Ile 184 and Leu 133, based on van der Waals interactions and not aromatic interactions. The introduction of electron withdrawing groups, such as halogen atoms, is therefore not enhancing affinity and optimisation on this side is with limited effect.

Molecular modelling studies were performed for PNB-081 with the $\mathrm{CCK}_{1}$ receptor (Figure $3 \mathrm{~b}$ ).The isobutyl group of the ligand interacted with a hydrophobic cave of the receptor, centred at Ala-14. The carbonyl group in the 2- position bond via hydrogen binding towards the CCK receptor with Arg- 9 and the N- atom of the lactame interacted with Glu-17. The 5-hydroxy-group of the ligand displayed interactions with of Asn-6, while the phenyl group has no interaction with tryptophan or phenylalanine.

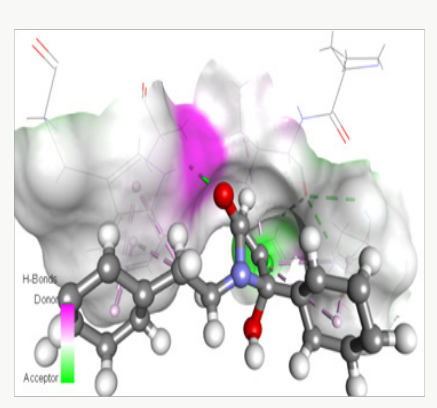

A

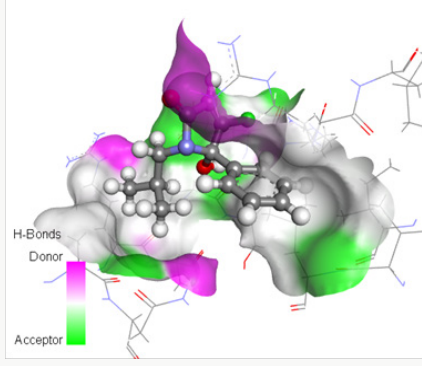

B

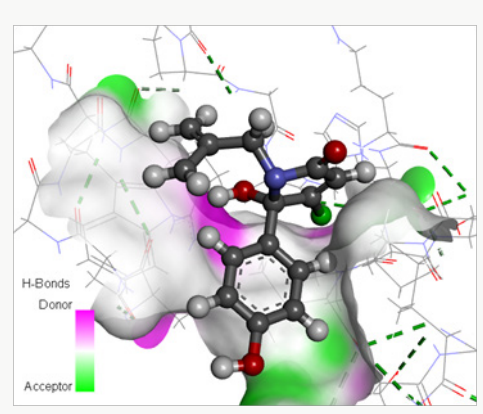

C

Figure 3: Molecular modelling of possible drug receptor interactions.

A. Docking of CCK antagonist PNB-001 into the CCK2 receptor.

B. Drug receptor interactions of PNB081 with the CCK1 receptor.

C. Metabolite receptor interactions of PNB081 with the CCK2 receptor.

$\mathrm{Pi}$ - alkyl interactions only may explain the small increase in binding affinity of the chlorinated analogue of PNB-081, based on interaction with Leu-29 and Ile-28. If the para phenyl position is not blocked by the chorine atom, most interestingly, the proposed metabolite can interact with the $\mathrm{CCK}_{2}$ receptor. It is supposed that PNB-081, is hydroxylated in the para phenyl position by $\mathrm{P} 450$ and this metabolite may interact with the $\mathrm{CCK}_{2}$ receptor via His 122 interaction, outlined in (Figure 3c). The role of metabolites is 
currently under investigations. Most interestingly hydroxylation may also enhance $\mathrm{CCK}_{1}$ affinity due to interactions with $\operatorname{Arg} 9$. Gaining dual CCK-gastrin antagonistic activity was found beneficial in analgesia potentiation [39] as well as for anxiolytics [40].

\section{Pharmacology}

\section{In Vitro Experiments using Isolated Tissue Preparations}

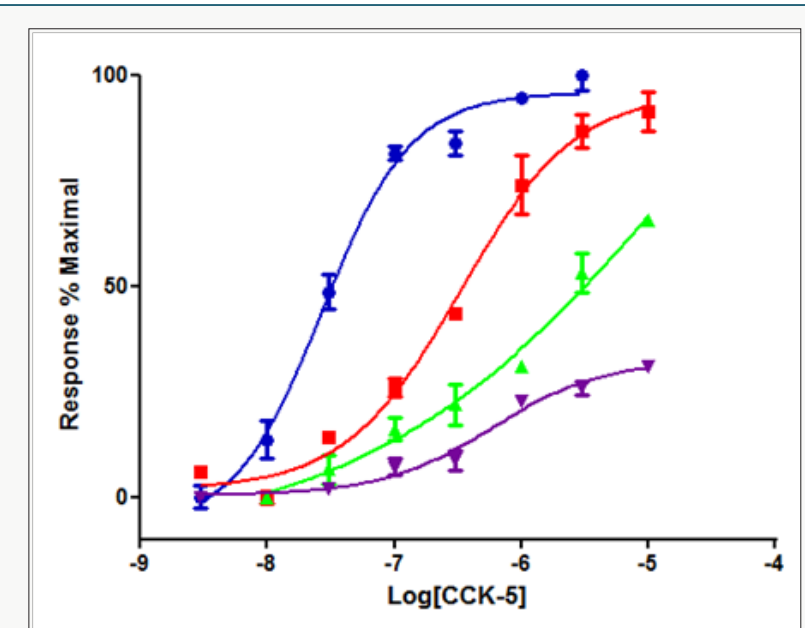

Figure 4: Responses to CCK-5 in the absence and presence of PNB-001; CCK-5, CCK-5 +10 nM PNB-001, CCK-5 +30 nMPNB-001, CCK-5 + 100 nM PNB-001; N = 2 for each data point.

The $\mathrm{CCK}_{2}$ selective phenyl ethyl derivative PNB-001, occurred a potent binding affinity and the CCK-gastrin -antagonism was studied [41] using penta-gastrin (CCK-5) induced contractions of the rat duodenum. Initially $\mathrm{CCK}_{4}$ was used, an agent, which trigged panic attacks in patients [42], but in vitro $\mathrm{CCK}_{4}$, has a low solubility and low potency in the micro-molar range. The best $\mathrm{CCK}_{2}$ selective agonist in vitro and in humans [43] is CCK-5 and therefore, pentagastrin was used to analyse the agonist or antagonist properties of PNB-001 (Figure 4). The concentration response curve of penta-gastrin, CCK-5, was recorded and shifted to the right by a nano molar concentration of PNB-001, thus confirming the antagonistic properties [44] of this ligand. $100 \mathrm{nM}$ of PNB-001 with 30 min of incubation time fully blocked the $\mathrm{CCK}_{4}$ and $\mathrm{CCK}_{5}$ induced contractions. For the 5 min incubation cycle, $10 \mathrm{nM}$ of PNB-001 shifted the CCK-5 concentration response curve to the right and from $30 \mathrm{nM}$ onwards, the antagonist showed a reduced maximum response. At high nano molar concentrations PNB-001 acted as non-competative antagonist. However, PNB-001 is now a confirmed potent and selective CCK-2/gastrin antagonist. Cholecystokinin, CCK8s, induced contractions of the guinea pig gall bladder [45] and this tissue based assay was adopted to the rat duodenum preparation.CCK-8s induced dose dependently contractions of the rat duodenum over a wide concentration range. These contractions were reduced dose dependently for PNB-081, which is outlined in (Figure. 5). Increased concentrations of the antagonist, PNB081 were added to the bath cumulatively and a shift of the curve to the right was observed. PNB-081 was acting as non-competitive antagonist. The problem with the gall bladder based assay is the limit of the tissue and the rat duodenum represented an excellent alternative with a good expression of the $\mathrm{CCK}_{1}$ receptor. In conclusion, the CCK antagonising properties of both molecules were clearly established using selective tissues and selective ligands. Under consideration of failed clinical trials for panic [46], positive pain results and our own results with respect to inflammation, our attention turned to a systematic in vivo evaluation of the molecules as a pain duo.

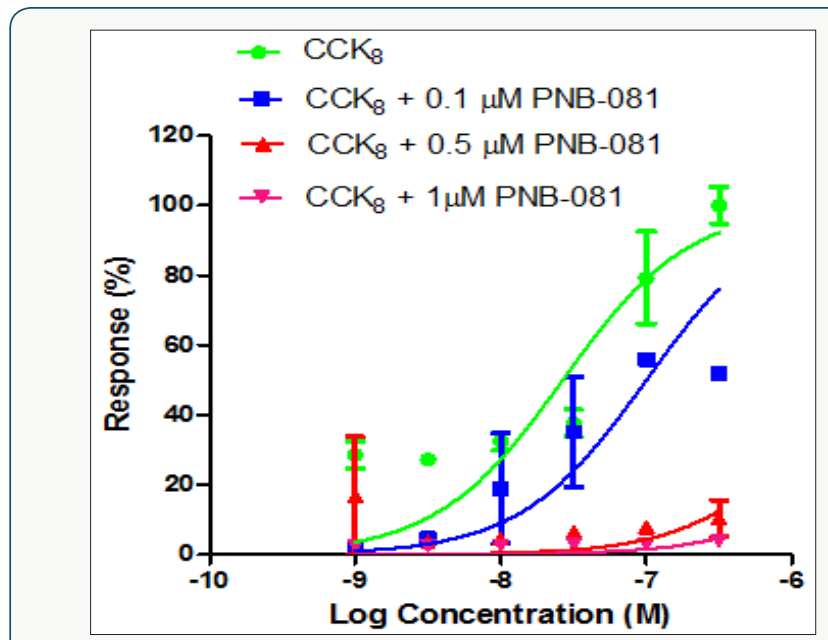

Figure 5: Mean cumulative concentration-response curves for CCK-8s in the presence and absence of PNB-081.

\section{In vivo Evaluation}

In order to evaluate the pain managing properties of the new agents, the hot plate assay and the tail immersion assay were used in rodents.

\section{Analgesic Activity of PNB-001}

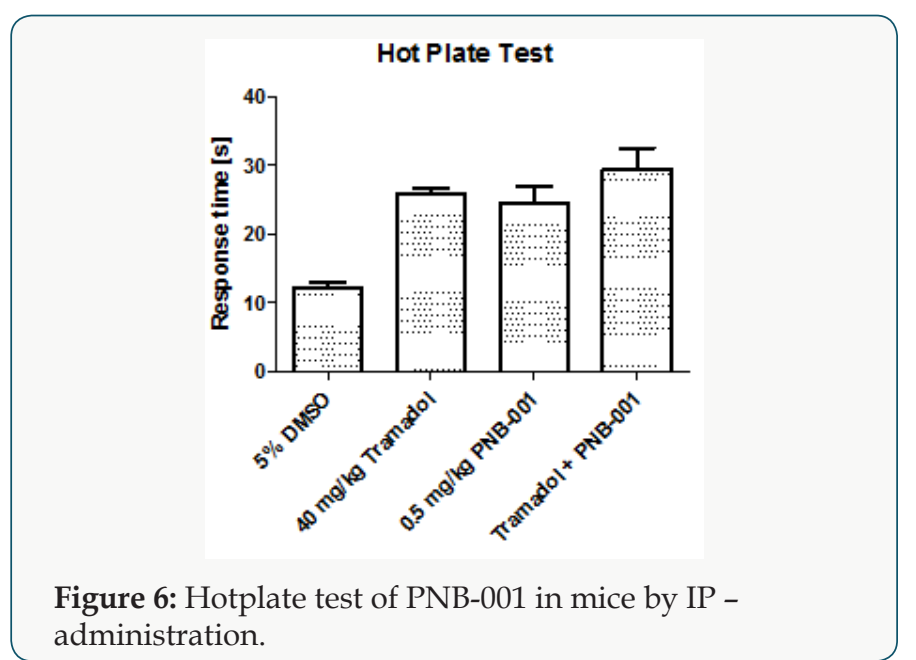

The anti-inflammatory activity of PNB-001 was previously reported by us using the formalin test and these results were confirmed. The small, but significant analgesic activity is due to the gastrin antagonising properties of the agent (Figure 6). Bar 1 is the 
baseline with a response time about $12 \mathrm{~s}$. The maximum analgesic effect in the hotplate test is $26 \mathrm{~s}$ for $40 \mathrm{mg} / \mathrm{kg}$ tramadol, a more than $100 \%$ of change from the control. The analgesic efficacy of $0.5 \mathrm{mg} / \mathrm{kg}$ PNB-001 by IP administration in mice as a single agent was found equivalent to $40 \mathrm{mg} / \mathrm{kg}$ tramadol by SC administration. Interestingly, there is no significant potentiation of tramadol analgesia with PNB-001. The selective $\mathrm{CCK}_{2}$ antagonist works as analgesic on its own in the hotplate test in mice. CCK antagonists potentiated the analgesia of opiates and usually (Lattmann, 2016) have no analgesic effect on their own. For Z-360 also, an interesting weak analgesic effect was observed [47] in the formalin test and CCK analgesia was linked with delta opiate activity [48].

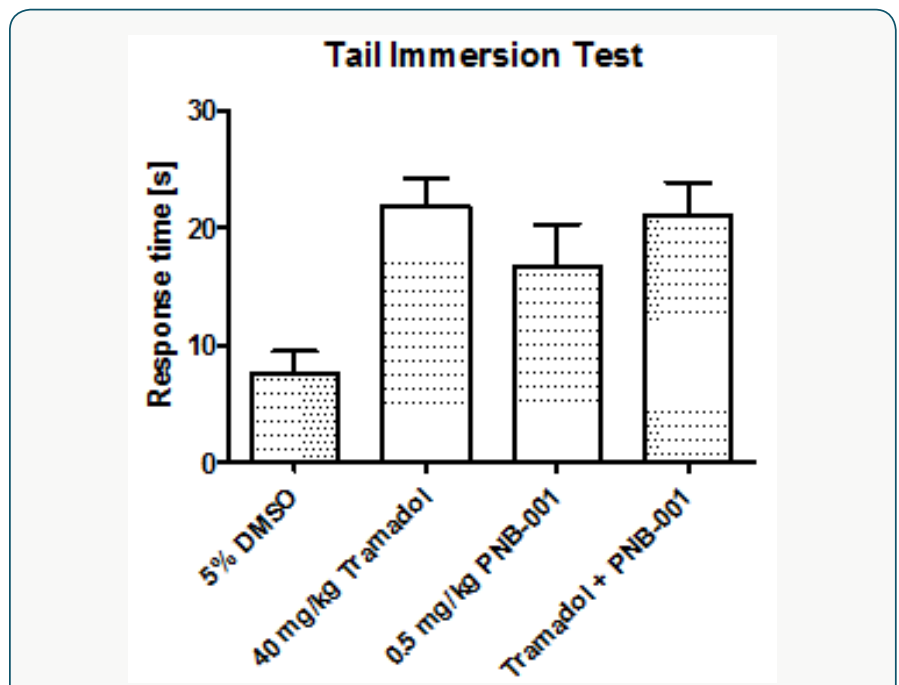

Figure 7: Tail immersion test of PNB-001 in mice by IP administration.

However, this analgesic activity was reconfirmed in a second standard analgesic assay in rodents using the tail immersion test and the results are outlined in (Figure 7). 5\% DMSO in water served as control in the tail immersion test in mice and tramadol at $40 \mathrm{mg}$ / $\mathrm{kg}$ was applied as analgesic standard. Test compound and standard were found not significantly different in this assay and a small potentiation of analgesia was observed, which was not significant. In principal, the same analgesic effect of the $\mathrm{CCK}_{2}$ antagonist PNB001 was observed for the hotplate and the tail immersion assay in mice without potentiation of analgesia [49]. Finally, the tail immersion test was performed in rats by oral administration. Rats were used as a second species and the route of administration was changed from IP to PO administration. The \% change from the vehicle was assessed and the results are outlined in (Figure 8). For the $1.5 \mathrm{mg} / \mathrm{kg}$ dose a $20 \%$ change from the vehicle was achieved, which increased dose dependently towards $20 \mathrm{mg} / \mathrm{kg}$. A $50 \%$ change from the control was observed for 5 and $10 \mathrm{mg} / \mathrm{kg}$, while the maximum response was found for $20 \mathrm{mg} / \mathrm{kg}$ in rats by PO administration after $1 \mathrm{~h}$. Rats seem to be loss responsive compared to mice, but the active dose range confirmed the oral bioactivity of about $10 \%$, which was obtained in PK analysis in vivo in rats and $0.5 \mathrm{mg} / \mathrm{kg}$ by IP administration was found equivalent to $5 \mathrm{mg} / \mathrm{kg}$ by oral administration.

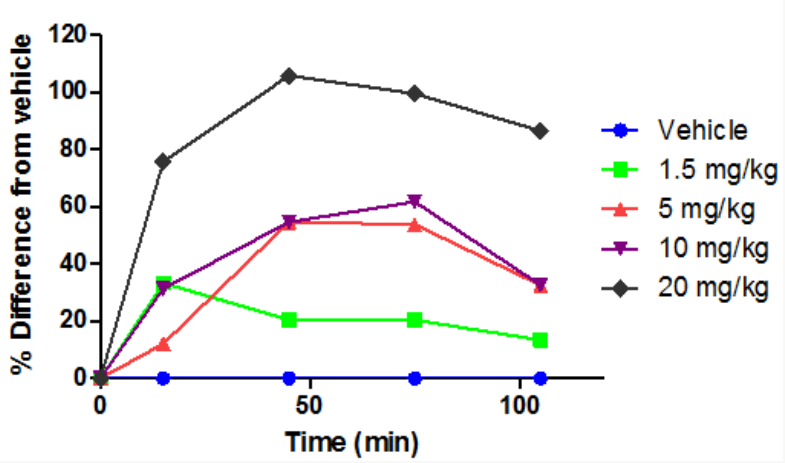

Figure 8: Dose range of PNB-001 in the tail immersion test by $\mathrm{PO}$ administration using rats.

\section{Potentiation of Opiate Analgesia}

The analgesic properties of PNB-001 were reported above and now it was focussed on the potentiation of morphine analgesia for our selected cholecystokinin antagonist PNB-081. The analgesic effect of morphine served as baseline and a linear correlation of the response time in s against the log dose of morphine from 2 to $16 \mathrm{mg} / \mathrm{kg}$ was obtained in the tail immersion tail immersion test in mice (Figure 9). An IP dose of 0.5 and $1.5 \mathrm{mg} / \mathrm{kg}$ of PNB081 potentiated the low morphine dose by factor 3 . The $2 \mathrm{mg} / \mathrm{kg}$ dose of morphine was shifted in presence of the CCK antagonist to an equivalent dose of $16 \mathrm{mg} / \mathrm{kg}$ morphine. Previously 2 different chemical classes, the anilino- benzodiazepines (Lattmann, 2006) and pyrazols (Lattmann, 2005) showed pain potentiation in the same standard assays.

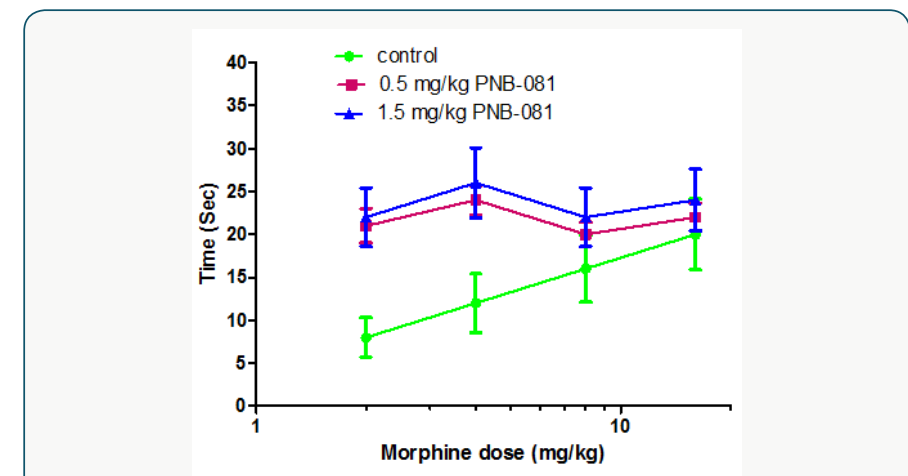

Figure 9: Potentiation of morphine analgesia of a dose range from $2-16 \mathrm{mg} / \mathrm{kg}$ in conjunction with 0.5 and 1.5 $\mathrm{mg} / \mathrm{kg}$ PNB-081in the tail immersion test.

\section{Opiate Tolerance}

Opiates and endorphines, so small organic molecules as well as peptides act as opiate agonist and produce analgesia. This analgesic effect is reversed by cholecystokinin, not gastrin. The established model of tolerance [50] is that, opiates induce the formation of cholecystokinin receptors and then cholecystokinin in form of $\mathrm{CCK}_{8 s^{\prime}}$ which is the main circulating form, neutralises opiate analgesia. A CCK antagonist does reverse this by blocking the newly formed CCK receptors. Experimentally, in line with the proposed model, 
a16 mg / kg dose of morphine, exhibited the anticipated analgesic effect and this analgesia faded out within days based on by daily sc administration of morphine (Figure 10). In presence of $1 \mathrm{mg}$ PNB081 administered intra peritoneally, no tolerance was observed and a continuous analgesic effect was observed over the duration of 4 days. This is clear confirmation that opiates and cholecystokinin are supposed to have opposing effects. Prolonged exposure to opiates induced the expression of CCK receptors and these CCK receptors were blocked by the CCK antagonist PNB-081. PNB-081 may be hydroxylated in vivo in mice gaining $\mathrm{CCK}_{2}$ selectivity [51]. Thus, a dual acting CCK antagonist may be produced, alleviating best the anti-nociceptive effects of morphine. To complete the CNS evaluation of PNB-081, a standard anxiolytic assay, the X-maze test was applied using mice (Figure 11). Mice in general dislike open areas and the anxiolytic diazepam $(4 \mathrm{mg} / \mathrm{kg}$ ) increased the time significantly they spent in open arms. For PNB-081 an anxiolytic effect was observed for the $1 \mathrm{mg} / \mathrm{kg}$ dose and this increase further for the $5 \mathrm{mg} / \mathrm{kg}$ dose by $\mathrm{PO}$ administration.

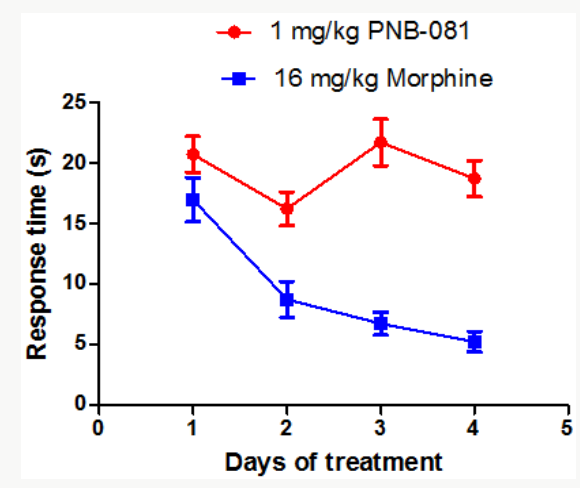

Figure 10: Reversal of opiate tolerance: $16 \mathrm{mg} / \mathrm{kg}$ of morphine as single agent and in conjunction with by PNB$081,1 \mathrm{mg} / \mathrm{kg}$, in the tail immersion test.

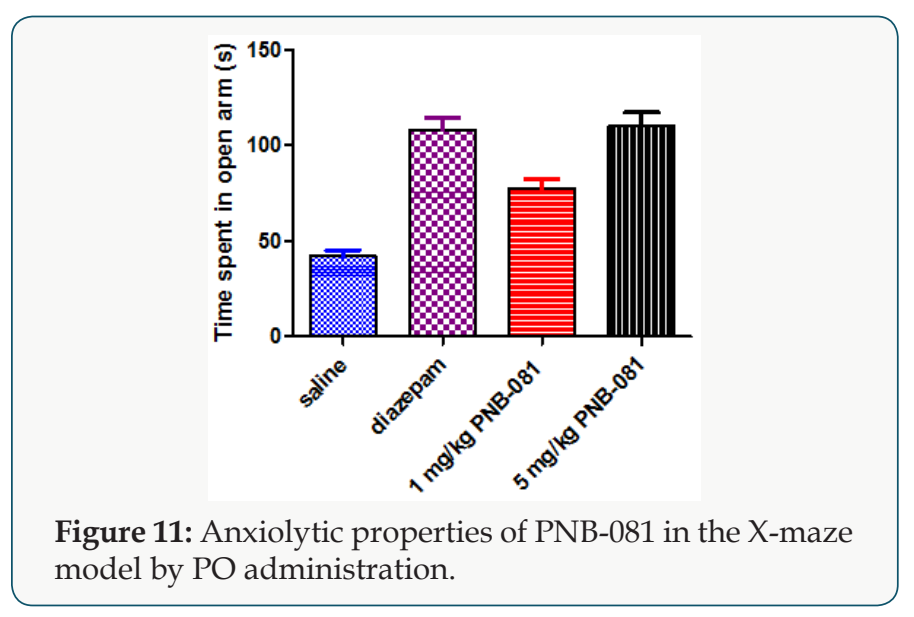

$\mathrm{CCK}_{4}$ induced panic in humans and generally $\mathrm{CCK}_{2}$ antagonists are associated with anxiolytic properties. Our finding are supported by other selected $\mathrm{CCK}_{1}$ antagonists [52] and the detection of $\mathrm{CCK}_{1}$ receptors in wide key areas of the brain [53]. Additionally, an estimate of the oral bioavailability (20-25\%) was derived from this assay. As part of the preclinical development, the pharmacokinetics of PNB-001 and PNB-081were fully analysed. In summary PNB001 showed a good half-life in dogs and rats. Protein binding was determined of $92.4 \%$ in human plasma and very high membrane permeability was determined by using the Caco-2 monolayer assay for both molecules. PNB-081 has anoral bioavailability of $25 \%$, PNB-001 of $10 \%$ in rats. In terms of regulatory toxicology, for PNB001 a slight increase of ALT was observed in dogs, but not in rats at doses $>1000 \mathrm{mg} / \mathrm{kg}$ and only after 90 days. PNB-081 entered preclinical toxicology.

\section{Conclusion}

The target molecules were synthesised in only 2 steps from one readily available starting material and will potentially deliver affordable therapeutic agents for a long term pain management. PNB-001, a gastrin antagonist, is reaching phase 1 clinical trial in April 2018 as anti-inflammatory analgesic. A first in class analgesic $\mathrm{CCK}_{2}$ antagonist was developed under the consideration of membrane penetration, half-life and bioavailability. On-going is a preclinical programme to extend general inflammation to neuroinflammation. Overall the cholecystokinin antagonist PNB-081 has shown the expected CNS profile with opiate potentiation and with anxiolytic properties. Pain as well as CNS trials are hard and unpredictable with high placebo response and therefore, for PNB081 pancreatitis may pose a possible route through regulatory approval. Potentiation of opiate analgesia, as well as the reversal of opiate tolerance are clear clinical features of the $\mathrm{CCK}_{1}$ antagonist PNB-081, which may help to alleviate the current opiate crisis in industrialised countries.

\section{Experimental Section}

\section{General Synthesis}

The chemicals were obtained from Aldrich (Gillingham, UK) and Lancaster (Lancaster, UK). Atmospheric pressure chemical ionisation mass spectroscopy (APCI), negative or positive mode, was carried out using a Hewlett-Packard 5989b quadrupole instrument (Vienna, Austria). Proton and Carbon NMR spectra were obtained on a Bruker AC 250 instrument (Follanden, Switzerland), operating at $250 \mathrm{MHz}$, calibrated with the solvent reference peak or TMS. IR spectra were plotted from $\mathrm{KBr}$ discs on a Mattson 300 FTIR Spectrometer. Melting points were recorded using a Stuart Scientific (Coventry, UK) apparatus and are uncorrected.

\section{Preparation of 3,4-Dichloro-5-Phenyl-5H-Furan-2-Ones, Reaction Intermediate 1}

Synthesis of 3,4-Dichloro-5-Phenyl-5H-Furan-2-one, Lactone A: Dry and powdered aluminium chloride (20g, $0.15 \mathrm{~mol})$ was added slowly to a mixture of mucochloric acid (16.9g, $0.1 \mathrm{~mol}$ ) and benzene / chlorobenzene $(250 \mathrm{ml})$. The reaction mixture was stirred overnight. It was then poured into a mixture of $100 \mathrm{~g}$ ice and $32 \mathrm{ml}$ concentrated hydrochloric acid. The organic layer was separated by separating funnel and washed with $3 \times 100 \mathrm{ml}$ water. The combined organic layers were dried over magnesium sulphate 
and the solvent was removed under vacuum. The oily residue was crystallized in n-hexane. Yield = 70\%; $\mathrm{mp}$ : 78-79 oC; $\mathrm{MS}(\mathrm{APCI}(+))$ : 195/197 (M+), 230/232 (M+1) m/z; 1H NMR (CDCl3) $250 \mathrm{MHz}: \delta$ $=7.22-7.51(\mathrm{~m}, 5 \mathrm{H}), 5.81(\mathrm{~s}, 1 \mathrm{H}) ; 13 \mathrm{C}$ NMR (CDCl3):165.3, 152.2, 139.8, 130.5, 129.3, 128.5, 127.4, 127.2, 121.2, 83.5; IR (KBr-disc) v max: 3445, 3074, 3035, 2959, 2056, 1768, 1630, 1499, 1457 $1294,1224,1028,910,772,705 \mathrm{~cm}^{-1}$

3,4-Dichloro-5-(4-Chloro-Phenyl)-5H-Furan-2-One, Lactone B: Yield = 69\% mp: 76-78 oC; MS (APCI(+)): 227/229/231 (M+1), 262/263/265 (M+) m/z; 1H NMR (CDCl3) $250 \mathrm{MHz}: \delta=$ 7.48 (m, 2H), 7.35 (m, 2H), 5.91 (s, 1H); 13C NMR (CDCl3) 165.3, 152.0, 136.6, 130.1, 129.6, 128.7, 121.3, 82.9; IR (KBr-disc) U max: 3451, 3075, 2952, 2051, 1769, 1636, 1497, 1419, 1289, 1231, 1027, $927,826,748,720 \mathrm{~cm}^{-1}$.

\section{Preparation of N-Substituted-4-Chloro-5-Hydroxy-5- Phenyl-1,5-Dihydro-Pyrrol-2-Ones}

Stage 2 Products; General Method: The relevant amine $(2.3$ times excess) was added to a solution of lactone $\mathrm{A}$ or $\mathrm{B}(0.7 \mathrm{~mol})$ in ether $(10 \mathrm{ml})$ and it was stirred on ice for 30 minutes, allowing to warm up to RT over time. The resultant mixture was poured into 5 $\mathrm{ml}$ of water and was separated by a separating funnel. The organic mixture was washed with water three times. The organic layer was dried over magnesium sulphate and the solvent was removed under vacuum. All compounds gave an oily solid, which were passed through a short silica gel column (80\% ether, $20 \%$ petrol ether). The resulting fractions were dried from excess solvent under a stream of argon to yield crystals.

4-Chloro-5-Hydroxy-1-Methyl-5-Phenyl-1,5-DihydroPyrrol-2-One 1: Yield = $75 \%$; mp: 146-148 oC; $M S(\operatorname{APCI}(+))$ : 193/195 (M+1), 224/226 (M+) m/z; 1H NMR (DMSO-d6)) 250 MHz: 7.29-7.48 (m, 5H), 6.49 (s, 1H), 2.08 (s, 3H)13C NMR (CDCl3) 168.1, 156.4, 134.1, 129.4, 128.9, 126.2, 121.3, 92.6, 24.5ppm. IR (KBr-disc): 3224, 3110, 2952, 2820, 2617, 2375, 2339, 1975, 1697, $1605,1453,1438,1258,1207,1065,992,856,764,704 \mathrm{~cm}^{-1}$.

4-Chloro-5-(4-Chloro-Phenyl)-5-Hydroxy-1-Methyl-1,5Dihydro-Pyrrol-2-One 2: Yield = $66 \%$; $\mathrm{mp}: 179-181$ oC; $\mathrm{MS}$ (APCI(+)): 227/229/231 (M+1), 258/260/262 (M+) m/z; 1H NMR (CDCl3) $250 \mathrm{MHz}$ 7.31-7.42 (m, 4H), 6.06 (s, 1H), 4.56-4.71 (bs, 1H), 2.60 (s, 3H) 13C NMR (CDCl3) 167.8, 156.0, 135.5, 132.8, 129.1, 127.8, 121.6, 92.2, 24.4 ppm. IR (KBr-disc) 3429, 3102, 2970, 2932, 2857, 1677, 1611, 1494, 1475, 1431, 1202, 1151, 1091, 988, $928,811,692 \mathrm{~cm}^{-1}$.

4-Chloro-5-Hydroxy-1-Isopropyl-5-Phenyl-1,5-DihydroPyrrol-2-One 3: Yield = $79 \%$; mp: 163-165 oC; MS (APCI(+)): 193/195 (M+1), 252/254 (M+) m/z; 1H NMR (CDCl3) $250 \mathrm{MHz}$ 7.40-7.51 (m, 5H), $6.14(\mathrm{~s}, 1 \mathrm{H}), 3.81(\mathrm{bs}, 1 \mathrm{H}), 3.42(\mathrm{~m}, 1 \mathrm{H}), 1.33 \&$ 1.21 (m, 6H)13C NMR (CDCl3) 167.5, 155.0, 135.0, 129.1, 128.5, 126.4, 122.4, 93.4, 45.6, 21.1, 20.0 ppm. IR (KBr-disc) 3227, 2990,
$2940,2365,2350,1956,1693,1615,1456,1428,1247,1131,1072$, $1009,934,847,747,697 \mathrm{~cm}^{-1}$.

4-Chloro-5-(4-Chloro-Phenyl)-5-Hydroxy-1-Isopropyl1,5-Dihydro-Pyrrol-2-One 4: Yield =69 \%; mp: 127-130 oC; MS (APCI(+)): 286/288/290 (M+) m/z; 1H NMR (CDCl3) $250 \mathrm{MHz}$ : 7.31(m, 4H), $6.06(\mathrm{~s}, 1 \mathrm{H}), 3.33(\mathrm{~m}, 1 \mathrm{H}), 1.25 \& 1.10(\mathrm{~m}, 6 \mathrm{H}) .13 \mathrm{C}$ NMR (CDCl3) 167.1, 154.0, 136.7, 133.4, 128.9, 128.0, 123.2, 92.9, 45.6, 20.1, 21.3 ppm. IR (KBr-disc) 3272, 2978, 2927, 1691, 1614, 1496, 1429, 1384, 1352, 1249, 1096, 1012, 936, 846, 801, $683 \mathrm{~cm}^{-1}$.

4-Chloro-1-Cyclopropyl-5-Hydroxy-5-Phenyl-1,5-DihydroPyrrol-2-One 5: Yield = $83 \%$; mp: 177-179 oC; MS (APCI(+)): 193/195 (M+1), 250/252 (M+) m/z;1H NMR (CDCl3) $250 \mathrm{MHz}: \delta$ $=7.41(\mathrm{~m}, 5 \mathrm{H}), 6.09(\mathrm{~s}, 1 \mathrm{H}), 3.50(\mathrm{~m}, 1 \mathrm{H}), 2.18(\mathrm{~m}, 1 \mathrm{H}), 0.95 \& 0.38$ (m, 4H); 13C NMR (CDCl3) 167.4, 154.8, 135.2, 129.2, 128.8, 126.1, 122.2, 93.5, 22.6, 3.8, 5.1 ppm.IR (KBr-disc) 3416, 3260, 3105, 3011, 2363, 2338, 1671, 1602, 1490, 1450, 1409, 1369, 1256, 1144, 1032, $939,833,752,702 \mathrm{~cm}^{-1}$.

4-Chloro-5-(4-Chloro-Phenyl)-1-Cyclopropyl-5-Hydroxy1,5-Dihydro-Pyrrol -2-One 6: Yield = 72 \%; mp: 169-171 oC; MS (APCI(+)): 284/286/288 (M+) m/z; 1H NMR (CDCl3) $250 \mathrm{MHz}$ 7.22 (m, 4H), 5.97 (s, 1H), 3.98(bs, 1H), $1.76(\mathrm{~m}, 1 \mathrm{H}), 0.24-0.99$ (m, 4H); 13C NMR (CDCl3) 165.8, 155.4, 144.2, 133.7, 129.0, 127.7, 122.2, 91.7, 22.6 , 3.7, 5.2 ppm.IR (KBr-disc) 3433, 3220, 3019, 2935, 2858, 1700, 1675, 1497, 1412, 1251, 1209, 1144, 1089, 1015, $940,844,802,679 \mathrm{~cm}^{-1}$.

4 - Chloro- 5 - Hyd roxy - 1 - I s obuty - 5 - Phe ny l- 1, 5 Dihydro-Pyrrol-2-One 7: Yield = $85 \%$; mp: 167-169 oC; MS (APCI(+)):266/268 (M+) m/z; 1H NMR (CDCl3) 250 MHz: 7.38$7.51(\mathrm{~m}, 5 \mathrm{H}), 6.24(\mathrm{~s}, 1 \mathrm{H}), 4.79$ (bs, $1 \mathrm{H}), 3.23 \& 2.18(\mathrm{~m}, 2 \mathrm{H})$, 1.71(m, 1H), 0.76 (m, 6H) 13C NMR (CDCl3) 168.5, 155.7, 137.1, 129.2, 128.7, 126.2, 121.7, 93.1, 47.6, 27.5, 20.4 ppm. IR (KBr-disc) $3237,3114,2965,2926,2881,2374,2343,1675,1614,1460,1416$, $1299,1251,1202,1150,1072,1027,878,758,696 \mathrm{~cm}-1$.

4-Chloro-5-(4-Chloro-Phenyl)-5-Hydroxy-1-Isobutyl1,5-Dihydro-Pyrrol-2-One 8: Yield = 66\%; mp: 155-158 oC; MS (APCI(+)):300/302/304 (M+) m/z; 1H NMR (CDCl3) $250 \mathrm{MHz}$ : $7.30(\mathrm{~m}, 4 \mathrm{H}), 6.19(\mathrm{~s}, 1 \mathrm{H}), 3.13(\mathrm{~m}, 1 \mathrm{H}), 2.49(\mathrm{~m}, 1 \mathrm{H}), 1.69(\mathrm{~m}, 1 \mathrm{H})$, 0.69 (t, J $=4.5 \mathrm{~Hz}, 6 \mathrm{H})$ 13C NMR (CDCl3) 163.3, 156.3, 139.4, 134.8, 129.1, 127.7, 122.3, 95.0, 47.6, 27.6, 20.4 ppm.IR (KBr-disc) 3426, $3252,2964,2850,1684,1406,1209,1095,817,743,703 \mathrm{~cm}^{-1}$.

4-Chloro-1-Cyclopentyl-5-Hydroxy-5-Phenyl-1,5-DihydroPyrrol-2-One 10: Yield = $81 \%$; mp: 180-182 oC; MS (APCI(+)): 278/280 (M+) m/z; $1 \mathrm{H} \mathrm{NMR} \mathrm{(CDCl3)} 250 \mathrm{MHz}: \delta=7.51(\mathrm{~m}, 5 \mathrm{H})$, 6.08 (s, 1H), 4.87 (bs, 1H), $3.59(\mathrm{~m}, 1 \mathrm{H}), 1.99(\mathrm{~m}, 2 \mathrm{H}), 1.81(\mathrm{~m}, 4 \mathrm{H})$, 1.46 (m, 4H); 13C NMR (CDCl3) 167.2, 155.0, 135.2, 129.1, 128.6, 126.5, 122.2, 93.3, 54.3, 30.0, 28.8, 24.5, 24.4 ppm.IR (KBr-disc) $3220,2961,2877,2373,2341,1684,1613,1448,1426,1248,1199$, $1141,1070,934,850,750,701 \mathrm{~cm}^{-1}$. 
4-Chloro-5-(4-Chloro-Phenyl)-1-Cyclopentyl-5-Hydroxy1,5-Dihydro-Pyrrol-2-One 11: Yield = 73 \%; mp: 157-159 oC; MS (APCI(+)): 312/314/316 (M+) m/z; 1H NMR (CDCl3) $250 \mathrm{MHz}: \delta$ $=7.42(\mathrm{~m}, 4 \mathrm{H}), 6.03(\mathrm{~s}, 1 \mathrm{H}), 4.99(\mathrm{bs}, 1 \mathrm{H}), 3.51-3.62(\mathrm{~m}, 1 \mathrm{H}), 1.97$ 2.19 (m,2H), 1.68-1.93 (m, 8H); 13C NMR (CDCl3) 167.1, 154.8, $135.2,133.9,128.9,128.0,122.3,93.0,54.3,30.0,28.9,24.5$ ppm. IR (KBr-disc) 3407, 3276, 2968, 2922, 2883, 2379, 2339, 1691, 1491, $1429,1367,1249,1203,1092,1013,932,843,787,709 \mathrm{~cm}^{-1}$.

4-Chloro-1-Hexyl-5-Hydroxy-5-Phenyl-1,5-DihydroPyrrol-2-One 12: Yield = $51 \%$; $\mathrm{mp}$ : 173-175 oC; $\mathrm{MS}$ (APCI(+)):294/296 (M+) m/z; 1H NMR (CDCl3) 250 MHz: 7.40 (m, $5 \mathrm{H}), 6.15(\mathrm{~s}, 1 \mathrm{H}), 4.76(\mathrm{bs}, 1 \mathrm{H}), 3.28(\mathrm{~m}, 1 \mathrm{H}), 2.91(\mathrm{~m}, 1 \mathrm{H}), 1.09-1.59$ (m, 8H), 0.78-0.92 (t, J = 7.1 Hz, 3H) 13C NMR (CDCl3) 168.0, 155.6, 134.9, 129.2, 128.7, 126.2, 121.8, 93.0, 40.2, 31.3, 28.7, 26.8, 22.5, 14.0 ppm. IR (KBr-disc) 3245, 2930, 2865, 1689, 1658, 1494, 1453, $1412,1365,1321,1150,1069,927,753,696 \mathrm{~cm}^{-1}$.

4-Chloro-5-(4-Chloro-Phenyl)-1-Hexyl-5-Hydroxy-1,5Dihydro-Pyrrol-2-One 13: Yield = 49 \%; mp: 169-172 oC; MS (APCI(+)):328/330/332 (M+) m/z; 1H NMR (CDCl3) $250 \mathrm{MHz}$ 7.31(m, 4H), $6.15(\mathrm{~s}, 1 \mathrm{H}), 3.24(\mathrm{~m}, 1 \mathrm{H}), 2.67(\mathrm{~m}, 1 \mathrm{H}), 1.04-1.69(\mathrm{~m}$, $8 \mathrm{H}), 0.74(\mathrm{t}, \mathrm{J}=6.3 \mathrm{~Hz}, 3 \mathrm{H})$ 13C NMR (CDCl3) 165.8, 155.7, 140.8, 136.9, 129.1, 127.8, 91.6, 40.3, 30.8, 29.1, 26.8, 22.6, 15.2 ppm. IR (KBr-disc) 3446, 2935, 2863, 1698, 1413, 1252, 1200, 1138, 1092, $1013,938,846,814,702 \mathrm{~cm}^{-1}$.

4-Chloro-1-Cyclohexyl-5-Hydroxy-5-Phenyl-1,5-DihydroPyrrol-2-One 14: Yield = 57 \%; mp: 170-172 oC; $\mathrm{MS}(\mathrm{APCI}(+))$ : 292/294 (M+) m/z; 1H NMR (CDCl3) 250 MHz: 7.26-7.61 (m, 5H), 6.08 (s, 1H), 3.77 (bs, 1H), $2.88(\mathrm{~m}, 1 \mathrm{H}), 1.21-2.07$ (m, 10H); 13C NMR (CDCl3) 163.9, 153.9, 135.0, 129.25, 128.9, 126.4, 122.9 , 96.0, 53.6, 32.8, 31.1, 29.8, 26.2 , 24.2 ppm.IR (KBr-disc) 3440, 2924, 2858, 2355, 2344, 1641, 1449, 1367, 1250, 1138, 1016, 996,742, $695 \mathrm{~cm}^{-1}$.

4-Chloro-1-(Phenyl)-5-Hydroxy-5-Phenyl-1,5-DihydroPyrrol-2-One 15: Yield = $48 \%$; mp: 168-171 oC; $M S(\operatorname{APCI}(+))$ : 314/316 (M+) m/z; 1H NMR (CDCl3) $250 \mathrm{MHz}: \delta=7.46(\mathrm{~m}, 5 \mathrm{H})$, 7.34 (m, 5H), 6.38 (s, 1H), 3.68 (bs, 1H);13C NMR (CDCl3) 168.9, 159.7, 136.9, 135.1, 132.4, 129.9, 129.0, 126.9, 123.0, 122.3, 122.2, 93.5; IR (KBr-disc) 3517, 3357, 3114, 2840, 2674, 2361, 2342, $1678,1607,1464,1412,1361,1208,1138,1071,988,755,700 \mathrm{~cm}$ 1

1-Benzyl-4-Chloro-5-Hydroxy-5-Phenyl-1,5-DihydroPyrrol-2-One 16: Yield = $71 \%$; mp: 165-167 oC; MS (APCI(+)): 300/302 (M+) m/z; 1H NMR (CDCl3) 250 MHz: 7.36 (m, 5H), 7.24 $(\mathrm{m}, 5 \mathrm{H}), 6.08(\mathrm{~s}, 1 \mathrm{H}), 4.69(\mathrm{~m}, 2 \mathrm{H}), 3.62$ (bs, 1H); 13C NMR (CDCl3) 167.9, 155.9, 137.6, 134.4, 129.3, 128.7, 128.4, 128.4, 127.3, 127.1, 126.4, 93.2, 43.4; IR (KBr-disc) 3446, 3279, 3098, 2931, 2850, $2374,2334,1684,1611,1456,1413,1349,1276,1205,1128,1051$, $696 \mathrm{~cm}^{-1}$.

1-Benzyl-4-Chloro-5-(4-Chloro-Phenyl)-5-Hydroxy-1,5Dihydro-Pyrrol-2-One 17: Yield = 59 \%; mp: 149-152 oC; MS
(APCI(+)): 334/336/338 (M+) m/z; 1H NMR (CDCl3) $250 \mathrm{MHz}: \delta$ $=7.33(\mathrm{~m}, 4 \mathrm{H}), 7.16(\mathrm{~m}, 5 \mathrm{H}), 6.09(\mathrm{~s}, 1 \mathrm{H}), 4.60(\mathrm{~m}, 2 \mathrm{H}), 13 \mathrm{C}$ NMR (CDCl3) 167.6, 155.4, 137.5, 135.3, 133.2, 129.1, 129.0, 128.9, 128.6, 128.4, 127.9, 127.4, 121.9, 92.6, 43.2; IR (KBr-disc) 3442, 2931, 2849, 2365, 2339, 1674, 1616, 1492, 1406, 1349 1272, 1199, $1094,1018,817,699 \mathrm{~cm}^{-1}$.

4-Chloro-5-Hydroxy-5-Phenyl-1-((S)-(-)-1-Phenyl-Ethyl)1,5-Dihydro-Pyrrol-2-One 18: Yield = $66 \%$; mp: 162-164 oC; MS (APCI(+)): 314/316 (M+) m/z; 1H NMR (CDCl3) $250 \mathrm{MHz}: \delta$ $=7.44(\mathrm{~m}, 7 \mathrm{H}), 7.08-7.25(\mathrm{~m}, 3 \mathrm{H}), 5.96(\mathrm{~s}, 1 \mathrm{H}), 4.16(\mathrm{~m}, 1 \mathrm{H}), 3.37$ (bs, 1H), 1.49 (m, 3H); 13C NMR (CDCl3) 167.3, 154.3, 142.5, 134.7, $129.4,128.7,128.4,127.7,127.3,126.4,123.0,93.8,53.5,18.8$ ppm. IR (KBr-disc) 3241, 2983, 2932, 2863, 2366, 2347, 1686, 1661, $1614,1494,1456,1425,1356,1258,1202,1025,931,855,755$, $692 \mathrm{~cm}^{-1}$.

4-Chloro-5-Hydroxy-5-Phenyl-1-((S)-(-)-1-Phenyl-Ethyl)1,5-Dihydro-Pyrrol-2-One 19: Yield = 4 \%; MS (APCI(+)):314/316 $(\mathrm{M}+) \mathrm{m} / \mathrm{z} ; 1 \mathrm{H}$ NMR (CDCl3) $250 \mathrm{MHz}: \delta=7.29-7.53(\mathrm{~m}, 7 \mathrm{H}), 6.95$ (m, 3H), $6.08(\mathrm{~s}, 1 \mathrm{H}), 4.78(\mathrm{~m}, 1 \mathrm{H}), 2.71(\mathrm{bs}, 1 \mathrm{H}), 1.63(\mathrm{~m}, 3 \mathrm{H})$.

4-Chloro-5-Hydroxy-1-Phenethyl-5-Phenyl-1,5-DihydroPyrrol-2-One 20: Yield = 89 \%; mp: 155-158 oC; MS (APCI(+)): 314/316 (M+) m/z; 1H NMR (CDCl3) $250 \mathrm{MHz}: \delta=7.09-7.53$ (m, 10H), $6.20(\mathrm{~s}, 1 \mathrm{H}), 3.74(\mathrm{~m}, 1 \mathrm{H}), 2.88-3.29(\mathrm{~m}, 3 \mathrm{H}), 2.65(\mathrm{~m}$, 1H); 13C NMR (CDCl3) 168.0, 155.7, 139.0, 134.6, 129.4, 128.85, 128.84, 128.6, 126.6, 126.2 , 121.8, 92.7, 41.9 , 34.6 ppm. IR (KBrdisc) $3433,3246,2929,2366,2334,1681,1658,1607,1455,1406$, $1251,1151,1128,1066,931,753,699 \mathrm{~cm}^{-1}$.

4-Chloro-5-(4-Chloro-Phenyl)-5-Hydroxy-1-Phenethyl1,5-Dihydro-Pyrrol-2-One 21: Yield = 45 \%, mp: 145-148 oC; MS (APCI(+)): 348/350/352 (M+) m/z; 1H NMR (CDCl3) $250 \mathrm{MHz}: \delta$ $=7.22-7.49(\mathrm{~m}, 7 \mathrm{H}), 7.12-7.18(\mathrm{~m}, 2 \mathrm{H}), 6.13(\mathrm{~s}, 1 \mathrm{H}), 3.68 \& 2.64$ (m, 2H), 2.88 (m, 2H); 13C NMR (CDCl3) 250 MHz: 167.7, 155.5, $138.8,135.5,133.3,129.1,128.8,128,7,127.7,126.7,121.9,92.3$, 42.0, 34.5; IR (KBr-disc) 3421, 3228, 2925, 2848, 2370, 2338, 1684, $1658,1606,1461,1406,1248,1190,1097,935,806,697 \mathrm{~cm}^{-1}$.

\section{Molecular Modelling}

For target preparation the protein structures, pdb identifier $1 \mathrm{HZN}$ for the $\mathrm{CCK}_{1}$ and $1 \mathrm{~L} 4 \mathrm{~T}$ for the $\mathrm{CCK}_{2}$-gastrin receptor were downloaded from the protein data bank (www.rcs.org) and docking was performed using Autodock Vina and Hex. After several docking trials for the $\mathrm{CCK}_{1} / \mathrm{CCK}_{2}$ receptor the results were analysed and visualized using Chimera and Designer studio 4.5. After visual inspection the results were presented to rationalize drug ligand interactions with the each CCK receptor subtype.

\section{Radio ligand Cholecystokinin Binding Assay}

$\mathrm{CCK}_{2}$ and $\mathrm{CCK}_{1}$ receptor binding assays were performed, by using guinea pig cerebral cortex or rat pancreas. Male guinea pig brain tissues were prepared according to the modified method described by Saita et al. [54] Pancreatic membranes were prepared 
as described by Charpentier et al. [55] Tissues were homogenized in ice cold sucrose $(0.32 \mathrm{M}, 25 \mathrm{ml})$ for 15 strokes at $500 \mathrm{rpm}$ and centrifuged at $13000 \mathrm{rpm}$ for 10 minutes. The supernatant was recentrifuged at $13000 \mathrm{rpm}$ for 20 minutes. The resulting pellet was re-dispersed to the required volume of buffer at $500 \mathrm{rpm}$ and stored in aliquots at 700C. Binding was achieved using radioligand125IBolton-Hunter labeled CCK, NEN at $25 \mathrm{pM}$. The samples were incubated with membranes $(0.1 \mathrm{mg} / \mathrm{ml})$ in 20 mMHepes, $1 \mathrm{mM}$ EGTA, $5 \mathrm{mM} \mathrm{MgCl} 2,150 \mathrm{mM} \mathrm{NaCl}$, at $\mathrm{pH} 6.5$ for $2 \mathrm{hrs}$ at RT and then centrifuged at $11000 \mathrm{rpm}$ for 5 minutes. The membrane pellets were washed twice with water and the bound radioactivity was measured in a Packard Cobra Auto-gamma counter (B5005). Binding assays were carried out with L-363, 260 as control.

\section{Isolated Tissue Preparations}

Male Sprague Dawley rats, weighing 200-250g were used and all animal care and experimental protocols adhered to the relevant laws and guidelines of the institution. The animals were housed under standard conditions of temperature $\left(25^{\circ} \mathrm{C}\right)$ with unrestricted access to food and water. The animals were sacrificed using cervical dislocation without anaesthesia. From the abdomen of the animals, the duodenum was carefully excised and washed with physiological solution. The mesentery of the tissue was removed and the lumen was gently flushed with Tyrode's solution to clear luminal contents. The prepared isolated tissue was rapidly incubated in Tyrode's solution maintained at 32oC and gassed with 95\% 02 / $5 \%$ C02.Tyrode's solution was freshly prepared daily (g/l): $\mathrm{NaCl}$, 8.0; $\mathrm{KCl}, 0.2$; $\mathrm{CaCl} 2$, 0.2; MgSO4, 0.1; $\mathrm{NaH2PO4,0.05;} \mathrm{NaHCO3,1.0;}$ Glucose,1.0.The main equipment used was the Radnoti single unit tissue bath system with a chamber capacity of $35 \mathrm{ml}$. Bath aeration with carbogen (O2 95\%, CO2 5\%) was maintained at a constant temperature $\left(32^{\circ} \mathrm{C}\right)$. The force in grams was measured with an isometric transducer linked to a power lab data acquisition system.

\section{General Procedure}

From the isolated tissue preparation, strips of appropriate length were mounted vertically in organ bath containing Tyrode's solution, under a tension of $1 \mathrm{~g}$ and allowed to equilibrate for 30 minutes. Agonists, such as $\mathrm{CCK}_{5}$ and CCK8Swere directly applied in the bath and antagonists were pre-incubated for $10 \mathrm{~min}$. Stock solutions of all test compounds including the standard were prepared in DMSO.

\section{CCK5, Penta-Gastrin and Cholecystokinin CCK8 Prepara- tions}

CCK8S was dissolved in distilled water to prepare a stock solution of $500 \mu \mathrm{M}$ solution, from which cumulative additions of increasing concentrations $(0.1 \mathrm{nM}, 1 \mathrm{nM}, 5 \mathrm{nM}, 10 \mathrm{nM}, 20 \mathrm{nM}$, $30 \mathrm{nM}$, and $40 \mathrm{nM}$ ) were tested to plot a dose response curve. Test molecules and Lorglumide were added to the organ bath 10 minutes before exposure to the next CCK8S serial concentrations. The same protocol was used for penta gastrin, $\mathrm{CCK}_{5}$.

\section{Animal Studies}

Experiments were conducted in male standard IRC mice obtained from the animal house, Faculty of Medicine, KhonKaen University. Each experimental group consisted of 6 animals and the treatment procedures were approved by the ethical committee, Faculty of Medicine, KhonKaen University (BEA030699).Mice were intraperitoneally injected with either test compound dissolved in $5 \%$ DMSO at the volume not more than $0.2 \mathrm{ml} /$ animal. At $30 \mathrm{~min}$ after treatment, animals were tested as described in the following sections.

Nociception Tests: The tail immersion test: The thermal response latency was measured by the tail immersion test. The animals were placed into individual restraining cages leaving the tail hanging freely. The tail was immersed into water at 500C. The response time, at which the animal reacted by withdrawing its tail from water, was recorded and the cut-off time was $10 \mathrm{sec}$ in order to avoid tissue damage. The base line withdrawal thresholds (BT) were recorded prior to the first injection. Test thresholds (TT) were measured $60 \mathrm{~min}$ after the second injection. The test thresholds were expressed as a percentage of Maximal Possible Effect (\% MPE) using the equation: $\%$ MPE $=\{($ TT-BT $) /(45-B T)\} \times 100$

DMSO (5 \%), pyrrolone (in 5 \% DMSO) was intraperitoneally injected and morphine was administered subcutaneously.

The Hot Plate Test: Mice were placed on a hot plate that was thermostatically maintained at $50 \mathrm{oC}$. A plexi glass box was used to confine the animal to the hot plate. The reaction time of each animal (either paw licking or jumping) was considered a pain response. The latency to reaction was recorded. For prevention of heat injury, the cut-off time of the test was $30 \mathrm{sec}$.

Anxiolytic Test: The elevated plus-maze: The wooden elevated plus-maze consisted of two open arms $(30 \times 10 \mathrm{~cm})$ without any walls, two enclosed arms of the same size with $5-\mathrm{cm}$ high side walls and end wall, and the central arena $(10 \times 10 \mathrm{~cm})$ inter connecting gall the arms. The maze was elevated approximately $30 \mathrm{~cm}$ from the floor. At the beginning of the experiment the mouse was placed in the central arena facing one of then closed arms. During a 5-min interval, the time animals spent in the open arms of the plus-maze was recorded. The mouse was considered to be in the open part when it had clearly crossed the line between the central arena and the open arm with its four legs.

\section{Statistical Methods}

The data were expressed as mean + SD and one-way analysis of variance (ANOVA) and supplementary Tukey test for pair wise comparison were tested to determine for any significant difference at $\mathrm{p}<0.05$.

\section{Acknowledgement}

The experimental work was partly supported by PNB Vesper 
Life Sciences. The animal studies were performed in compliance with relevant laws and institutional guidelines

\section{References}

1. Maton P, Sutliff V, Jensen R, Gardner JD (1985) Carbobenzoxy amino acids: Structural requirements for cholecystokinin receptor antagonist activity. Am J Physiol 248(4 Pt 1): 479-484.

2. Herranz R (2003) Cholecystokinin Antagonists: Pharmacological and Therapeutic Potential. Med Res Rev 23(5): 559-605.

3. Mawe GM (1991) the role of cholecystokinin in ganglionic transmission in the guinea-pig gall-bladder. J Physiol 439: 89-102.

4. Jorpes E, Mutt V (1966) Cholecystokinin and Pancreozymin, one single Hormone?. Acta Physiol Scand 66: 196-202.

5. Mc Donald IM (2001) $\mathrm{CCK}_{2}$ receptor antagonists. Exp Opin Ther Patents 11:445.

6. Bock MG, Di Pardo RM, Mellin EC, Newton RC, Veber, DF, et al. (1994) Second-generation benzodiazepine CCK-B antagonists. Development of subnanomolar analogues with selectivity and water solubility. J Med Chem 37(6): 722-724.

7. Lattmann E, Arayarat P (2003) From CNS-drugs to anti-neoplastic agents: Cholecystokinin (CCK) antagonists as modern anti-cancer agents. KKU Science J 31: 178.

8. Dourish CT, S Ravard (1990) Cholecystokinin and anxiety. Trends Pharmacol Sci 11(7): 271-273.

9. Rasmussen K, Czachura, JF, Stockton, ME, Howbert JJ (1993) Electrophysiological effects of diphenylpyrazolidinone cholecystokinin-B and cholecystokinin-A antagonists on midbrain dopamine neurons. J Pharmacol Exp Ther 264(1): 480-488.

10. Dourish CT, Rycroft W, Iversen, SD (1989) Postponement of satiety by blockade of brain cholecystokinin-B receptors. Science 245(4925): 1509-1511.

11. Bradwejn J, Koszycki D, Meterissian G (1990) Cholecystokinin tetrapeptide induces panic attacks in patients with panic disorder. Can J Psychiatry 35(1): 83-85.

12. Hughes J, Boden P, Costallt B, Domeney A, Kelly E, et al. (1990) Development of a class of selective cholecystokinin type B receptor antagonists having potent anxiolytic activity. Proceedings of the National Academy of Sciences USA 87(17): 6728-32.

13. Trivedi K, Bharat J (1994) Cholecystokinin receptor antagonists: Current status. Curr Med Chem 1: 313.

14. Chang R, Lotti V, Monaghan R, Birnbaum J, Stapley EO, et al. (1985) A potent non peptide cholecystokinin antagonist selective for peripheral tissues isolated from Aspergillus alliaceus. Science 230(4722): 177-179.

15. Lattmann E, Billington DC, Poyner DR, Howitt SB, Offel M (2001) Synthesis and evaluation of Asperlicin analogues as non-peptidal Cholecystokinin-antagonists. Drug Des Discov 17(3): 219-30.

16. Evans BE, Rittle KE, Bock MG, M DiPardo, RM Freidinger, et al. (1988) Methods for drug discovery: Development of potent, selective, orally effective cholecystokinin-A antagonists. J Med Chem 31 (12): 22352246.

17. Hahne W, Jensen R, Lemp G, Gardner JD (1981) Proglumide and benzotript: Members of a different class of cholecystokinin receptor antagonists. Proceedings of the National Academy of Sciences USA 78(10): 6304-6308.

18. Makovec F, Chistè R, Bani M, Pacini MA, Setnikar I, et al. (1985) New glutaramic acid derivatives with potent competitive and specific cholecystokinin-antagonistic activity. Arzneimittelforschung 35(7): 1048-1051.

19. Noble F, Wank SA, Crawley JN, Bradwejn J, Seroogy KB et al. (1999) International Union of Pharmacology XXI. Structure, Distribution, and Functions of Cholecystokinin Receptors. Pharmacol Rev 51(4): 745-781.

20. Woodruff GN, Hughes J (1991) Cholecystokinin antagonists. Annu Rev Pharmacol Toxicol 31: 469-501.

21. Hughes J, Woodruff GN (1992) Neuropeptides function and clinical applications. Arzneimittelforschung 42(2A): 250-255.

22. Meyer T, Caplin ME, Palmer DH, Valle JW, Larvin M, et al. (2010) A phase $\mathrm{Ib} / \mathrm{Ila}$ trial to evaluate the $\mathrm{CCK}_{2}$ receptor antagonist Z-360 in combination with gemcitabine in patients with advanced pancreatic cancer. Eur J Cancer 46(3): 526-533.

23. Offel M, Lattmann P, Singh H, Billington DC, Bunprakob Y, et al. (2006) Synthesis of substituted 3-anilino-5-phenyl-1,3-dihydro-2H-1,4benzodiazepinones and their evaluation as cholecystokinin ligands. ArchPharm (Weinheim) 339(4): 163-173.

24. Lattmann E, Singh H, Boonprakob J, Lattmann P, Sattayasai J (2006) Synthesis and evaluation of $\mathrm{N}$-(3oxo-2,3-dihydro-1Hpyrazol-4-yl)-1Hindole-carboxamide as cholecystokinin antagonists. J Pharm Pharmacol 58(3): 393-401.

25. Lattmann E, Sattayasai J, Boonprakob J, Pornthip Lattmann, Harjit Singh (2005) Synthesis and evaluation of N-(5-methyl-3-oxo1,2-diphenyl-2,3dihydro-1H-pyrazol-4yl)-N-phenylureas as Cholecystokinin antagonists. Arzneimittelforschung 36(38): 251.

26. Lattmann E, Sattayasai J, Boonprakob Y, S Dunn, et al. (2008) Cholecystokinin antagonists (part 1): Antinociceptive, anxiolytic and antidepressant effects of $\mathrm{N}$-(5-methyl-3-oxo-1,2-diphenyl-2,3-dihydro$1 \mathrm{H}$-pyrazol-4-yl)-N'-phenylureas and carboxamides. Drug Discov Ther 2(3): 156-167.

27. Lattmann E, Billington DC, Poyner DR, Arayarat P, Howitt SB, et al. (2002) Combinatorial solid phase synthesis of multiply-substituted 1,4-benzodiazepines and affinity studies on the $\mathrm{CCK}_{2}$ receptor (Part 1). Drug DesDiscov 18(1): 9-21.

28. Lattmann E, Sattayasa J, Billington DC, Poyner DR, Puapairoj P, et al. (2002) Synthesis and evaluation of N1-substituted-3-propyl-1,4benzodiazepine-2-ones as Cholecystokinin $\left(\mathrm{CCK}_{2}\right)$-receptor ligands. J Pharm Pharmcol 54(6): 827-834.

29. Lattmann E, Sattayasai J, Schwalbe CH, Boonprakob Y, Dunn S, et al. (2016) Analgesic Effects of 5-Alkyloxy-4-amino-2(5H)-furanones as Cholecystokinin-2 antagonists. Arch Pharm (Weinheim) 349(6): 456465.

30. Yekkirala AS, Roberson DP, Bean BP, Woolf CJ (2017) Breaking barriers to novel analgesic drug development. Nat Rev Drug Discov 16(8): 545564 .

31. DourishC, O'Neill M, Coughlan J, Kitchener SJ, Hawley D, et al. (1990) The selective CCK-B receptor antagonist L-365,260 enhances morphine analgesia and prevents morphine tolerance in the rat. Eur J Pharmacol 176(1): 35-44.

32. Simpson KH, Serpell M, McCubbins TD, et al. (2002) A multi-dose study: Management of neuropathic pain in patients using a CCK antagonist devazepide (DEVACADE $囚$ ) as adjunct to strong opioids. In World Congress of $10^{\text {th }}$ IASP; San Diego, CA, U.S.A.

33. Lattmann E, Russell ST, Schwalbe CH, A Shortt, PN Balaram, et al. (2016) Cholecystokinin-1 receptor antagonists: 5-hydroxy-5-aryl-pyrrol-2ones as anticancer agent. Med Chem Commun 7: 1138.

34. Lattmann E, Sattayasai J, Narayanan R, N Ngoc, D Burrell, et al. (2017) Cholecystokinin-2/gastrin antagonists: 5-hydroxy-5-aryl-pyrrol-2-ones 
as anti-inflammatory analgesics for the treatment of inflammatory bowel disease. Med Chem Commun 3: 680.

35. Baber S, Dourish T, HillR (1989) The role of CCK caerulein, and CCK antagonists in nociception. Pain 39(3): 307-328.

36. Lattmann E, Ayuko WO, Kinchinaton D, Langley CA, Singh H, et al. (2003) Synthesis and evaluation of 5 -arylated $2(5 \mathrm{H})$-furanones and 2-arylated pyridazin-3(2H)-ones as anticancer agents. J Pharm Pharm 55(9): 12591265.

37. Lattmann E, Sattayasai N, Schwalbe CS, Niamsanit S, Billington DC, et al. (2006) Novel anti-bacterials against MRSA: synthesis of focussedcombinatorial libraries of tri-substituted $2(5 \mathrm{H})$-furanones. Curr Drug Discov Technol 3(2): 125-134.

38. Ponnusamy S, Lattmann E, Lattmann P, Thiyagarajan T, Padinjarethalakal BN, et al. (2016) Novel, isoform-selective, cholecystokinin A receptor antagonist inhibits colon and pancreatic cancers in preclinical models through novel mechanism of action. Oncol Rep 35(4): 2097-2106.

39. Lattmann E, Boonprakob Y, Sattayasai J (2008) Part 2. Long term in vivo/ in vitro evaluation of the Cholecystokininantagonists:N-(5-methyl-3oxo-1,2-diphenyl-2,3-dihydro-1H-pyrazol-4-yl)-N'-phenylurea MPP and carboxamide MPM. Drug Discov Ther 2(6): 344-352.

40. Revel L, Mennuni L, Garofalo P, Makovec F (1998) CR 2945: A novel CCKB receptor antagonist with anxiolytic like activity. Behav Pharmacol 9(3): 183-194.

41. D'Amato M, Stamford IF, Bennett A (1991) Studies of three non-peptide cholecystokinin antagonists (devazepide, lorglumide and loxiglumide) in human isolated alimentary muscle and guinea-pig ileum. $\mathrm{Br}$ Pharmacol 102(2): 391-395.

42. BradwejnJ, Koszycki D, Couetoux du Tertre A, et al. (1994) The panicogenic effects of cholecystokinin-tetrapeptide are antagonized by L-365,260, a central cholecystokinin receptor antagonist, in patients with panic disorder. Arch Gen Psychiatry 51(6): 486-493.

43. D’Amato M, Stamford I, Bennett A (1990) The effects of cholecystokinin octa-peptide on human isolated alimentary muscle. $\mathrm{Br} J$ Pharmacol 100(1): 126-130.

44. Kenakin T, Jenkinson S, Watson C (2006) Determining the Potency and Molecular Mechanism of Action of Insurmountable Antagonists. J Pharmacol Exp Ther 319(2): 710-723.
45. Bishop L, Gerskowitch V, Hull R, Shankley NP, Black JW (1992) Combined dose-ratio analysis of cholecystokinin receptor antagonists, devazepide, lorglumide and loxi-glumide in the guinea-pig gall bladder. $\mathrm{Br} \mathrm{J}$ Pharmacol 106(1): 61-66.

46. Sramek JJ, Kramer MS, Reines SA, Cutler NR (1994) Pilot study of a CCKB antagonist in patients with panic disorder: Preliminary findings. Anxiety 1(3): 141-143.

47. Yoshinaga K, Horii T, Hamano H, Eta R, Ozaki T, et al. (2010) Pharmacological evaluation of analgesic effects of the cholecystokinin2 receptor antagonist Z-360 in mouse models of formalin- and cancerinduced pain. Biol Pharm Bull 33(2): 244-248.

48. Chang R, Rigdon G, Howard J, McNutt RW (1993) A novel, potent and selective nonpeptidic delta opioid receptor agonist BW373U86.J Pharmacol Exp Ther 267(2): 852-857.

49. Friedrich A, Gebhart G (2000) Effects of Spinal Cholecystokinin Receptor Antagonists on Morphine Antinociception in a Model of Visceral Pain in the Rat. J Pharmacol Exp Ther 292(2): 538-544.

50. Wiesenfeld Hallin Z, Xu XJ (1996) The role of cholecystokinin in nociception, neuropathic pain and opiate tolerance. Regul Pept 65(1): 23-28.

51. Zhou Y, Sun Y, Zhang Z, Han JS (1993) Increased release of immunoreactive cholecystokinin octapeptide by morphine and potentiation of mu-opioid analgesia by CCKB receptor antagonist L-365,260 in rat spinal cord. Eur J Pharmacol 234(2-3): 147-154.

52. Ballaz S, Barber A, Fortuño A, Del Río J, Martin Martínez M, et al. (1997) Pharmacological evaluation of IQM-95,333, a highly selective CCKA receptor antagonist with anxiolytic-like activity in animal models. $\mathrm{Br} \mathrm{J}$ Pharmacol 121(4): 759-767.

53. Zarbin M, Innis R, Wamsley J, Snyder SH, Kuhar MJ (1983) Autoradiographic Localization of Cholecystokinin Receptors in Rodent Brain. J Neurosci 3(4): 877-906.

54. Saita Y, Yazawa H, Honma, Y, Nishida A, Miyata K, et al. (1994) Characterization of YM022: its CCKB/gastrin receptor binding profile and antagonism to CCK-8-induced $\mathrm{Ca}^{2+}$ mobilization. Eur J Pharmacol 269(2): 249-254.

55. Charpentier B, Pelaprat D, Durieux C, Dor A, Reibaud M, et al. (1988) Cyclic cholecystokinin analogues with high selectivity for central receptors. Proc Natl Acad Sci, USA 85(6): 1968-1972.

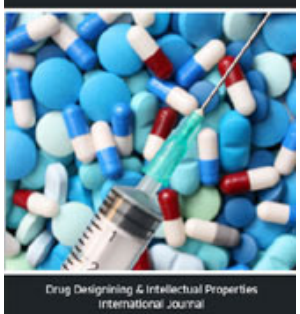

\section{Drug Designing \& Intellectual}

Properties International Journal

\section{Assets of Publishing with us}

- Global archiving of articles

- Immediate, unrestricted online access

- Rigorous Peer Review Process

- Authors Retain Copyrights

- Unique DOI for all articles 